\title{
A Teoria do Prospecto: Estimação da Função Utilidade e da Função Ponderação das Probabilidades para uma Amostra Específica
}

\section{Prospect Theory: Utility and Weighting Function Estimation for an Especific Sample}

\author{
Marcos Falleiro* \\ Carlos Eduardo Lobo e Silva** \\ Silvio H. T. Tai***
}

\begin{abstract}
Resumo: A partir da teoria do prospecto de Kahneman e Tversky (1979), este artigo investiga a função utilidade e a função ponderação das probabilidades de economistas da Pontifícia Universidade Católica do Rio Grande do Sul (PUCRS) e, portanto, seu comportamento perante o risco, comparando-os aos resultados da literatura. Para tanto, é realizado um experimento com alunos e professores da graduação e pósgraduação da PUCRS usando um método de aplicação baseado em Gonzalez e Wu (1999) e parcialmente novo, o que permite minimizar efeitos de ordem e efeitos de escala. De posse das respostas, são estimados os parâmetros da função utilidade e da função de ponderação das probabilidades de cada participante. Os resultados encontrados mostram que os economistas da PUCRS apresentam um comportamento distinto da média encontrada na literatura econômica: possuem uma função utilidade mais linear e uma discriminação das probabilidades menor que os resultados da literatura. A extensão dos resultados sugere a existência de relevantes diferenças de comportamento dentro do grupo pesquisado de acordo com suas características demográficas. Além da obtenção dos resultados finais, este artigo tem o objetivo adicional de contribuir para o debate em uma área de importância crescente e ainda pouco desenvolvida no Brasil.
\end{abstract}

Palavras-chave: Teoria do prospecto. Tomada de decisão. Economia comportamental. Experimentos econômicos em laboratório.

\begin{abstract}
Using Kahneman and Tversky's (1979) prospect theory this paper investigates the utility function and the weighting function of economists from Pontifícia Universidade Católica do Rio Grande do Sul (PUCRS, Brazil) and, therefore, their risk behavior and compare them with the results found in the literature. For this purpose, an experiment was undertaken with students and professors from the Economic Department of PUCRS using a application method that is partially from Gonzalez and Wu (1999) and partially new, which allowed to minimize order effects and scales effects. With the participants answers

\footnotetext{
* $\quad$ Mestre em Economia pela Pontifícia Universidade Católica do Rio Grande do Sul (PUCRS). Doutorando em Economia pelo Programa de Pós-Graduação em Economia da Universidade Federal do Rio Grande do Sul (UFRGS).E-mail: falleiro.marcos@gmail.com

** Doutor em Economia pela University of Illinois at Urbana-Champaign. Professor titular da PUCRS. E-mail: carlos.silva@pucrs.br

*** Doutor em Economia Université Paris I - Panthéon Sorbonne. Professor adjunto da PUCRS. E-mail: silvio.tai@pucrs.br
} 
we estimated the parameters of the utility function and of the weighting function of each individual. The results found show that economists from PUCRS have a distinct behavior of the average found in the economic literature; they have a more linear utility function and they discriminate the probabilities less than the results from the literature. The extension of the results suggests there are significant differences in behavior among the researched group accordingly with their demographic characteristics. Moreover, this paper has the additional purpose of contributing for the discussion in an area of growing importance and poorly developed in Brazil.

Keywords: Prospect theory. Decision making. Behavioral economics. Laboratory experiments.

JEL Classification: D81; D01; C91.

\section{Introdução}

A teoria da utilidade esperada (TUE) é amplamente aceita como o melhor modelo de análise normativa sobre tomadas de decisões em um contexto de risco ou de incerteza. No entanto, há um consenso na literatura de que a TUE não fornece uma descrição adequada do processo decisório quando este é analisado descritivamente (TVERSKY; KAHNEMAN, 1992). ${ }^{1}$

Muitos tentaram aprimorar a TUE para que a teoria incorporasse de forma adequada os resultados das pesquisas empíricas. ${ }^{2}$ Dentre estes, destacam-se a teoria do prospecto (TP) (KAHNEMAN; TVERSKY, 1979) e a teoria do prospecto cumulativa (TVERSKY; KAHNEMAN, 1992), que procuram entender como as pessoas tomam suas decisões em situações de incerteza.

As mudanças e os novos conceitos trouxeram alterações na forma da função utilidade e a inclusão de uma função de ponderação das probabilidades. A função utilidade na TP possui uma forma côncava, para ganhos, e convexa, para perdas, apresentando a forma de um "S" na qual as perdas são mais íngremes que os ganhos em decorrência da aversão à perda. Com relação à função de ponderação das probabilidades, possui uma forma de "S" invertido, sendo côncava, para pequenas probabilidades, e convexa, para médias e grandes probabilidades.

É possível assumir formas para a função utilidade e para a função ponderação das probabilidades e, assim, estimar-se parâmetros que permitem averiguar as formas dessas funções, tanto no nível individual quanto no nível agregado. Exemplos são encontrados nos trabalhos de Kahneman e Tversky (1979), Tversky e Kahneman (1992), Gonzalez e Wu (1999), Tecles e Rezende (2012), Booij, Praag e Kuilen (2010), entre outros. O foco principal desses trabalhos é observar o valor absoluto dos parâmetros da função de utilidade para ganhos e para perdas, o coeficiente

\footnotetext{
1 As principais críticas e paradoxos relacionados à TUE podem ser encontrados nos estudos de Allais (1953) e Kahneman e Tvesrky (1979).

2 Starmer (2000) traz um resumo dos principais modelos desenvolvidos.
} 
de aversão à perda e as diferentes formas possíveis para a função de ponderação das probabilidades.

Este artigo tem como foco comparar uma amostra de economistas da Pontifícia Universidade Católica do Rio Grande do Sul (PUCRS) com a literatura, estimando-se parametricamente a função utilidade e a função ponderação das probabilidades para averiguar se existem diferenças nos parâmetros entre a literatura e a amostra aqui estimada. Além disso, alguns dos estudos mencionados no parágrafo anterior citam a existência de possíveis diferenças (e a necessidade de expansão das pesquisas nesse escopo) entre os parâmetros agregados por grupos. Nesse sentido, em uma extensão exploratória dos resultados, propõe-se uma forma de se aprofundar as pesquisas sobre diferentes comportamentos de acordo com gênero, escolaridade e idade.

Para se coletar os dados necessários às estimações, usualmente são realizados experimentos com pequenas variações entre eles, nos quais indivíduos são questionados a indicar suas preferências com relação a uma série de apostas. $\mathrm{O}$ objetivo dos questionários é encontrar os equivalentes de certeza de cada indivíduo para cada aposta, ou seja, achar o valor que faz o indivíduo ficar indiferente entre um ganho certo e a aposta. Seguindo-se esse protocolo, realiza-se um experimento com os alunos e os professores para se descobrir suas preferências e coletar os dados necessários para as estimações.

O segundo diferencial desta pesquisa em relação a outros estudos diz respeito à metodologia utilizada. Com o objetivo de tornar o questionário possível de ser respondido em um tempo menor e, consequentemente, ser um fardo cognitivo menor para os participantes - o que pode reduzir as imprecisões das respostas —, o questionário foi aplicado de uma forma inédita: cada indivíduo escolheu as seis preferências que determinavam o equivalente de certeza uma após a outra, e não separadamente. ${ }^{3}$ Dessa forma, uma vez observadas as probabilidades e os resultados envolvidos na aposta, o participante podia escolher rapidamente todas as preferências relacionadas com essa aposta. Esse fato, somado com a aleatoriedade das questões, minimiza possíveis efeitos de ordem e efeitos de escala. Os detalhes metodológicos são explorados na seção correspondente.

Por último, é importante salientar que, enquanto na literatura econômica o tema é relativamente novo, tendo sua base teórica sido consolidada em 1992, no Brasil o tema tem sido pouco explorado, lacuna que este estudo pretende ajudar a preencher.

Este trabalho apresenta mais quatro seções, além desta introdução: a segunda realiza uma breve revisão da TP; a terceira apresenta o método e detalha os participantes, os procedimentos e os instrumentos utilizados, além do modelo de

3 Metodologia aplicada nos trabalhos de Kahneman e Tversky (1979), Abdellaoui, Bleichrodt e L'Haridon (2008) e Tecles e Resende (2012). 
estimação; a quarta discute os resultados e realiza uma análise comparativa com resultados obtidos em outros trabalhos; a quinta traça as considerações finais.

\section{Teoria do Prospecto}

A TP afirma que os indivíduos tomam suas decisões em duas fases distintas (KAHNEMAN; TVERSKY, 1979). Na primeira, o problema é editado de acordo com princípios heurísticos e regras que servem para simplificar a tomada de decisão. Então, a partir dessa edição dos prospectos, o tomador de decisão atribui valores para cada um dos prospectos e escolhe o de maior valor $(V)$, segundo a função:

$$
\mathrm{V}(\mathrm{q})=\sum \pi\left(\mathrm{p}_{\mathrm{i}}\right) \cdot \mathrm{v}\left(\mathrm{x}_{\mathrm{i}}\right)
$$

A escala $\pi$ associa cada probabilidade com um peso de decisão da forma $\pi(p)$, sendo que $\pi$ não é uma medida de probabilidade, mas uma medida de peso da probabilidade sobre o prospecto, e pode ocorrer que $\pi(p)+\pi(1-p)<1$. A escala $v$ associa a cada resultado $x$ um valor $v(x)$, e $q$ é um prospecto qualquer.

Além de incluir a edição dos prospectos como primeira fase de decisão, outra importante contribuição da TP é a escala $v$. Enquanto na TUE a escala $u$ (usada no lugar da escala $v$ ) mede a utilidade de resultados a partir do nível de riqueza do indivíduo, a TP mensura a função valor a partir dos desvios de um ponto de referência. Isso possibilita que os ganhos e as perdas possam ser interpretados de formas diferentes. Assim, o ponto de referência pode ser interpretado como o status quo, $x=0$, e a forma da função utilidade seria como mostrado na Figura 1: côncava para ganhos e convexa para perdas, com inclinação mais íngreme para perdas. 
Figura 1 - Valoração de resultados na teoria do prospecto

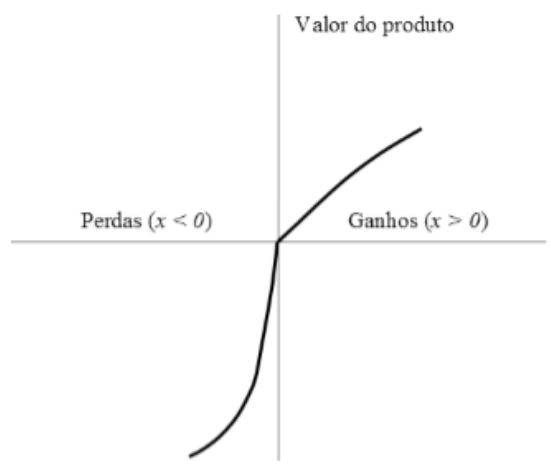

Fonte: Starmer (2000).

A função de ponderação $\pi(p)$, por sua vez, segundo Kahneman e Tversky (1979, p. 280), "[...] mede o impacto de eventos na desejabilidade de prospectos [...]". Essa função apresenta propriedades como a sobreponderação para valores pequenos de probabilidade, $\pi(p)>p$, quando $p$ for pequeno. Além disso, para pequenas probabilidades, a função também apresenta subaditividade, formalmente, $\pi(r p)>\mathrm{r} \pi(p)$. Outra propriedade, mencionada anteriormente, é que pode ocorrer $\pi(p)+\pi(1-p)<1$, e isso vale para $0<p<1$. A essa propriedade, Kahenman e Tversky dão o nome de subcerteza. Por último, a propriedade chamada de subproporcionalidade indica que a proporção dos pesos de decisão correspondentes se aproxima mais da unidade quando as probabilidades são mais baixas do que quando são mais altas. Essa propriedade impõe restrições na forma de $\pi$, e ela se mantém se, e somente se, $\log \pi$ for uma função convexa de $\log p$. Assim, $\pi$ é relativamente rasa nos intervalos abertos, mas perto dos limites extremos muda abruptamente, mais precisamente onde $\pi(0)=0$ e $\pi(1)=1$.

A teoria do prospecto cumulativa (TPC), também proposta por Tversky e Kahneman (1992), incorpora elementos da TUE dependente de rank de Quiggin (1982) e, dessa forma, não permite que ocorram violações da dominância estocástica como permite a TP. A TPC trouxe, ainda, a possibilidade de diferenciação entre a função para ganhos e a função para perdas, a possibilidade de se avaliar qualquer número finito de resultados e a mudança na forma da função de ponderação, além de dois novos conceitos psicológicos — a sensibilidade decrescente e a aversão à perda. 
A sensibilidade decrescente decorre do fato de que, quanto mais distantes do ponto de referência estiverem as variações monetárias, menor será o impacto psicológico. Então, por exemplo, a diferença entre ganhos de \$30 e \$40 parecerá maior que entre $\$ 200$ e $\$ 210$, considerando-se como ponto de referência o valor $\$ 0$ (zero). O conceito também funciona para a função de ponderação das probabilidades. Nesse caso, os pontos de referência são a probabilidade um, que significa que a "certeza irá acontecer", e a probabilidade zero, que significa que a "certeza não irá acontecer". Isso se traduz como uma distorção das probabilidades mais acentuada perto desses pontos de referência, que vai diminuindo e suavizando na medida em que se distanciam dos extremos. A consequência, portanto, dessa sensibilidade decrescente, na função ponderação das probabilidades, é uma forma de "s" invertido, que, a princípio, é côncava em relação à linha de 45 graus e depois torna-se convexa a partir de um certo ponto (ver Figura 2, o ponto de inflexão é denotado por $p^{*}$ ), o qual pode variar entre indivíduos.

Figura 2 - Função ponderação com a forma de "s" invertido

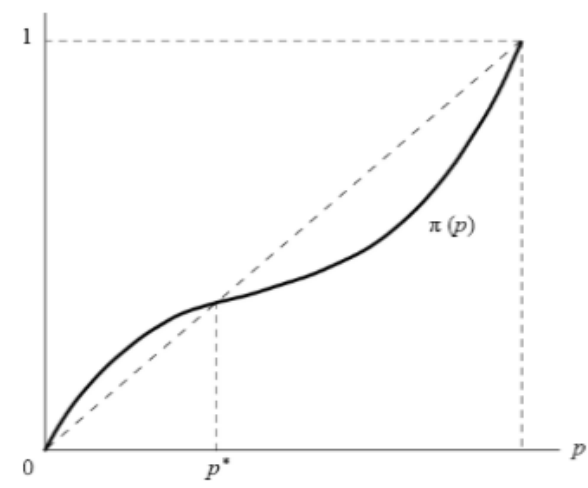

Fonte: Starmer (2000).

O segundo conceito psicológico - a aversão à perda - justifica que a função seja mais íngreme para perdas do que para ganhos e, além de ser intuitivo (conceito presente na diferença entre o valor que o indivíduo aceita pagar por um bem e o valor que o indivíduo exige para vender o mesmo bem), é apoiado por evidências empíricas que mostram que as pessoas não acham atrativas apostas da forma $(x|0,5 ;-x| 0,5)$.

Para expandir a TPC para um número maior que dois resultados e possibilitar funções diferentes para ganhos e perdas, Tversky e Kahneman (1992) seguem Starmer e Sugden (1989) e consideram a função de valor como: 


$$
\mathrm{V}(\mathrm{f})=\mathrm{V}\left(\mathrm{f}^{+}\right)+\mathrm{V}\left(\mathrm{f}^{-}\right)
$$

sendo que

$$
\mathrm{V}\left(\mathrm{f}^{+}\right)=\sum_{\mathrm{i}=0}^{\mathrm{n}} \pi_{\mathrm{i}}^{+} \mathrm{V}\left(\mathrm{x}_{\mathrm{i}}\right)
$$

e

$$
\mathrm{V}\left(\mathrm{f}^{-}\right)=\sum_{-\mathrm{m}}^{0} \pi_{\mathrm{i}}^{-} \mathrm{V}\left(\mathrm{x}_{\mathrm{i}}\right)
$$

Dessa forma, resultados não negativos são avaliados dentro de $\mathrm{V}\left(\mathrm{f}^{+}\right)$e resultados não positivos dentro de $\mathrm{V}\left(\mathrm{f}^{-}\right)$, permitindo que $\pi$ e $v$ assumam formas diferentes para ganhos e perdas.

Para v, Tversky e Kahneman (1992) assumem que:

$$
v(x)=\left\{\begin{array}{c}
x^{\alpha} \text { se } x \geq 0 \\
-\lambda(-x)^{\beta} \text { se } x<0
\end{array}\right.
$$

sendo $\lambda$ o coeficiente de aversão à perda. Para $\pi$ :

$$
\begin{gathered}
\pi_{\mathrm{n}}^{+}=\mathrm{w}^{+}\left(\mathrm{p}_{\mathrm{n}}\right), \pi_{-\mathrm{m}}^{-}=\mathrm{w}^{-}\left(\mathrm{p}_{-\mathrm{m}}\right) \\
\pi_{\mathrm{i}}^{+}=\mathrm{w}^{+}\left(\mathrm{p}_{\mathrm{i}}+\ldots+\mathrm{p}_{\mathrm{n}}\right)-\mathrm{w}^{+}\left(\mathrm{p}_{\mathrm{i}+1}+\ldots+\mathrm{p}_{\mathrm{n}}\right), 0 \leq \mathrm{i} \leq \mathrm{n}-1 \\
\pi_{\mathrm{i}}^{-}=\mathrm{w}^{-}\left(\mathrm{p}_{-\mathrm{m}}+\ldots+\mathrm{p}_{\mathrm{i}}\right)-\mathrm{w}^{-}\left(\mathrm{p}_{-\mathrm{m}}+\ldots+\mathrm{p}_{\mathrm{i}-1}\right), 1-\mathrm{m} \leq \mathrm{i} \leq 0
\end{gathered}
$$

Sendo -m o pior resultado e $\mathrm{n}$ o melhor. Isso torna a teoria dependente de rank, como a de Quiggin (1982), e também dependente de sinal.

Por último, Tversky e Kahneman (1992) propõem uma alteração na forma da função ponderação que eles mesmos tinham proposto. A nova forma possui um desenho de "s" invertido (ver Figura 2) e seria representada pela seguinte equação:

$$
w^{+}(p)=\frac{p^{\gamma}}{\left(p^{\gamma}+(1-p)^{r}\right)^{1 / \gamma}}
$$

para ganhos, e

$$
w^{-}(p)=\frac{p^{\delta}}{\left(p^{\delta}+(1-p)^{\delta}\right)^{1 / \delta}}
$$

para perdas. 
O mais importante produto das alterações feitas por Tversky e Kahneman (1992) na teoria do prospecto, segundo eles mesmos, seria o padrão quaternário de atitudes com relação ao risco gerado pelas formas das funções adotadas. Esse padrão implica que, para prospectos não mistos, ou seja, apenas positivos ou negativos, existe uma aversão ao risco para ganhos com alta probabilidade e para perdas com pequena probabilidade. Por outro lado, ganhos com pequena probabilidade e perdas com alta probabilidade implicam comportamentos de busca pelo risco. ${ }^{4}$

\subsection{Avanços na Função de Ponderação das Probabilidades}

Após o trabalho de Tversky e Kahneman (1992), houve avanços tanto na interpretação psicológica quanto na forma da função de ponderação das probabilidades. Um dos mais importantes avanços é o trabalho de Gonzalez e Wu (1999), que dão uma interpretação psicológica mais completa da função ponderação das probabilidades, chamando a atenção para duas características que eles nomeiam de discriminabilidade e atratividade. A primeira estaria ligada ao grau de curvatura da função e a segunda, à elevação da função.

A discriminabilidade está muito atrelada ao conceito de sensibilidade decrescente que Tversky e Kahneman (1992) trouxeram à tona. Ela significa que a sensibilidade da variação de uma unidade na probabilidade muda ao longo da escala de probabilidade.

A Figura 3 ajuda a compreender os dois casos extremos da discriminabilidade. Considerando-se a função $w_{2}$, nota-se que possui maior sensibilidade perto dos pontos de referência e menor em grande parte das probabilidades intermediárias. Um indivíduo que possui essa função de ponderação das probabilidades detecta o fato de que a "certeza irá ocorrer" ou de que a "certeza não irá ocorrer". Entretanto, todas as probabilidades intermediárias são tratadas de maneira muita similar, como um genérico "talvez". O outro caso extremo é representado pela função $w_{1}$, quase linear. Um indivíduo com essa função de ponderação das probabilidades é capaz de distinguir pequenas variações na probabilidade, fazendo com que sua função apresente alta sensibilidade a mudanças de probabilidade. ${ }^{5}$

4 É importante destacar que o padrão quaternário surge como uma notável generalização do comportamento sob risco. Tversky e Kahneman (1992, p. 307-308) mostram o resultado do experimento realizado por eles com a porcentagem da amostra que apresenta esse padrão de comportamento (mais de $80 \%$ da amostra segue esse comportamento). Além disso, os autores, no mesmo artigo, explicam que vários experimentos observaram o mesmo padrão. $\mathrm{w}_{1}$ tem maior discriminabilidade que uma função $\mathrm{w}_{2}$ dentro do intervalo $\left[\mathrm{q}_{1}, \mathrm{q}_{2}\right]$ sempre que $\mathrm{w}_{1}$ $(p+\varepsilon)-w_{1}(p)>w_{2}(p+\varepsilon)-w_{2}(p)$ para todo $p$ limitado entre 0 e $1, \varepsilon>0, p, p+\varepsilon \in\left[\mathrm{q}_{1}, \mathrm{q}_{2}\right] . "$ 
Figura 3 - Os dois casos extremos da discriminabilidade

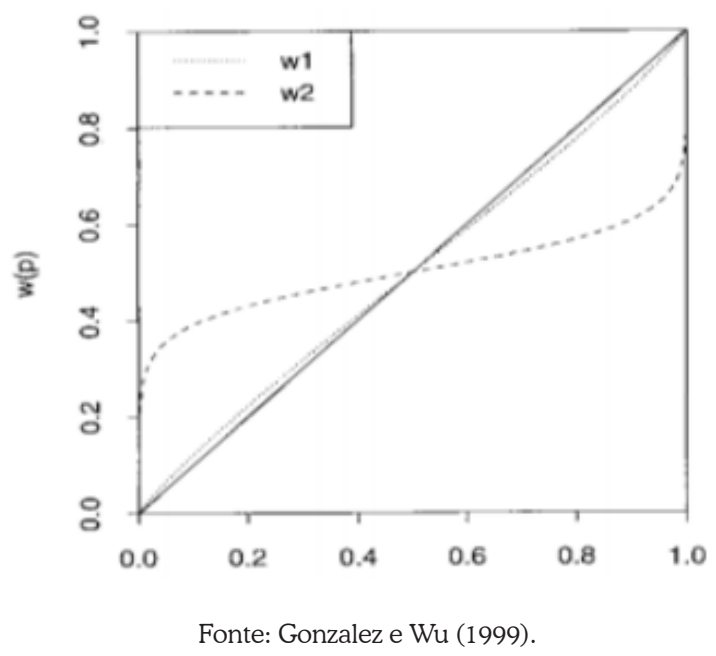

O conceito de atratividade, por sua vez, corresponde ao nível absoluto de $w$. Ele é necessário para indicar se a função de ponderação está localizada acima da linha de 45 graus, abaixo desta ou, então, em qual ponto cruza essa linha de identidade, visto que o conceito de sensibilidade decrescente apenas modela a forma da função de ponderação (primeiro côncava e depois convexa).

Dessa forma, um indivíduo pode pesar a probabilidade de 0,5 dentro da sua função de ponderação como $\mathrm{w}_{1}(0,5)=0,6$, enquanto outro indivíduo pode pesar

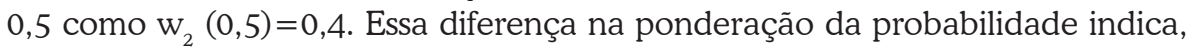
considerando-se apenas ganhos e também que os dois indivíduos estão perante aposta idêntica, que o indivíduo 1 acha a aposta mais atrativa que o indivíduo 2 , pois aquele designa um peso maior para probabilidade 0,5 . A Figura 4 mostra um exemplo de dois indivíduos com diferentes níveis de atratividade com relação a um domínio qualquer. 
Figura 4 - Funções de ponderação que diferem em elevação

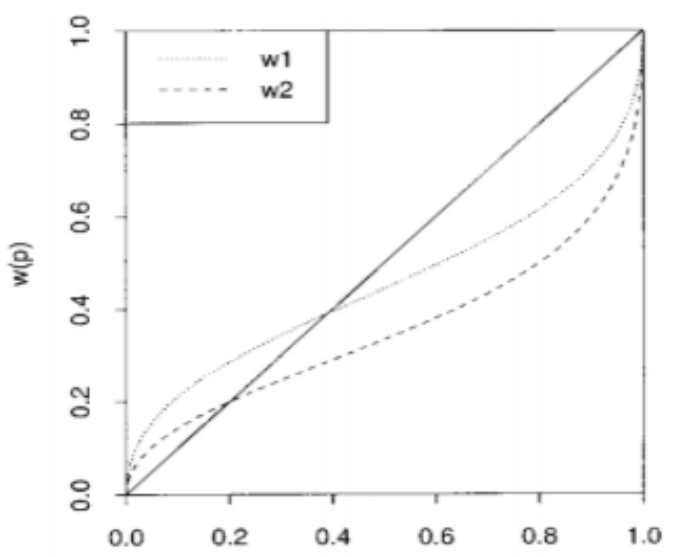

Fonte: Gonzalez e Wu (1999).

Portanto, Gonzalez e Wu (1999) colocam duas propriedades psicológicas independentes que caracterizam a função de ponderação das probabilidades e apresentam uma forma funcional para $w$. Segundo os próprios, se existem duas propriedades lógicas independentes, então seria possível modelar $w$ como uma função de dois parâmetros. Como mencionado, um parâmetro representa a curvatura (discriminabilidade) e o outro representa a elevação (atratividade) da função. Dessa forma, pode-se apresentar a função como:

$$
w(p)=\frac{\delta p^{\gamma}}{\delta p^{\gamma}+(1-p)^{\gamma}}
$$

em que $\delta=\exp \tau,^{6}$, o parâmetro $\gamma$ controla a curvatura da função e o parâmetro $\delta$ controla a elevação.?

Segundo Booij, Praag e Kuilen (2010), que compilam informações de uma série de estudos que estimaram as funções da TP, as formas mais usadas para a função de ponderação das probabilidades são: a equação 11, de Gonzalez e Wu (1999), que é a forma que este trabalho utiliza; as equações 9 e 10, de Tversky e Kahneman (1992); e a forma proposta por Prelec (1998).

$6 \quad$ A equação parte da igualdade $\log \frac{w(p)}{1-w(p)}=\gamma \log \frac{p}{1-p}+\tau$, e é rearranjada para adquirir a forma apresentada na equação 11.

7 Essa forma funcional para foi apresentada pela primeira vez por Goldstein e Einhorn (1987). 


\section{Método}

O método consistiu em uma estimação paramétrica da função utilidade e da função ponderação das probabilidades. A estimação dessas funções, considerando-se a teoria do prospecto, envolve, na maioria das vezes, um experimento. Ele é essencial para que seja possivel encontrar os equivalentes de certeza - variável dependente da estimação — necessários à estimação paramétrica ou não paramétrica.

Quatro características podem ser citadas como identificadoras de um experimento: a) não há tentativa de enganar os participantes, sua participação requer um consentimento livre e esclarecido; b) o contexto é abstrato; c) as instruções são integralmente publicadas, tornando possível replicá-las; d) há um incentivo monetário na tentativa de replicar as condições do mundo real. ${ }^{8}$

Os equivalentes de certeza necessários à estimação, mencionados no parágrafo anterior, são encontrados através de questionários aplicados aos indivíduos. O procedimento comum a vários autores é apresentar aos questionados uma aposta com dois resultados possíveis, cada um ligado a uma probabilidade (com as duas probabilidades somando um). Dessa forma, tenta-se encontrar o valor monetário de ganho certo, o equivalente de certeza, que faria o indivíduo ficar indiferente entre a aposta e esse valor monetário.

Com os equivalentes de certeza elucidados através dos questionários aplicados, a estimação pode ser feita de duas formas: parametricamente ou não parametricamente. Existem vantagens e desvantagens para os dois modos. Sinteticamente, o modo não paramétrico tem a vantagem de não assumir formas a priori para as funções a serem estimadas. No entanto, o questionário requer mais perguntas, mais tempo para ser respondido e, como a estimação é feita por partes, pode ocorrer propagação de erros (GONZALEZ; WU, 1999). Exemplos de estimações sob a teoria do prospecto usando formas não paramétricas podem ser encontrados nos trabalhos de Gonzalez e Wu (1999) e Abdellaoui, Bleichrodt e Paraschiv (2007). O modo paramétrico, por sua vez, é mais simples e mais fácil de estimar, mas os resultados ficam condicionados às formas paramétricas escolhidas. Caso essas formas sejam mal escolhidas ou mal especificadas, os resultados serão distorcidos. Estimações paramétricas podem ser encontradas nos trabalhos de Tversky e Kahneman (1992), Gonzalez e Wu (1999), Abdellaoui, Bleichrodt e L'Haridon (2008) e Booij, Praag e Kuilen (2010).

8 Dois nomes podem ser mencionados no campo da economia experimental: o pesquisador John A. List, que realizou experimentos testando a TUE contra a TP (LIST, 2003), e o pesquisador Glenn W. Harrison. Um resumo sobre diferentes tipos de experimentos econômicos pode ser encontrado no estudo de Harrison e List (2004). 
O método paramétrico utilizado neste trabalho foi o de máxima verossimilhança. Formas funcionais para as funções $v$ e $w$ devem ser assumidas para tornar a estimação possível.

É importante salientar que, para prospectos com dois resultados que se mantêm apenas no domínio dos ganhos, a TP se iguala à TPC. Dessa forma, de acordo com a regra de edição de prospectos da segregação, proposta por Kahneman e Tversky (1979), e tratando-se de prospectos envolvendo ganhos, pode-se ver a equação 1 como:

$$
\mathrm{V}(\mathrm{x}, \mathrm{p} ; \mathrm{y}, 1-\mathrm{p})=\mathrm{w}(\mathrm{p})[\mathrm{V}(\mathrm{x})-\mathrm{V}(\mathrm{y})]+\mathrm{V}(\mathrm{y})
$$

O próximo passo é assumir formas funcionais para as funções e representar a variável dependente como o equivalente de certeza. Considerando-se a equação 5 , a qual provê a forma funcional de $\mathrm{x}^{\alpha}$ para resultados não negativos de $\mathrm{v}$, e a equação 11, que provê a forma para função de ponderação das probabilidades, pode-se reescrever a equação 12 como:

$$
E C_{i}=\left[\frac{\delta p^{\gamma}}{\delta p^{\gamma}+(1-p)^{\gamma}}\left(x_{i}^{\alpha}-y_{i}^{\alpha}\right)+y_{i}^{\alpha}\right]^{1 / \alpha}
$$

Esse é o modelo no qual os parâmetros $\alpha, \gamma$ e $\delta$ deverão ser estimados.

\subsection{Participantes, Material e Procedimentos}

Todos os participantes do experimento são alunos e/ou professores do curso de economia da PUCRS, incluindo graduandos, mestrandos, doutorandos e alguns doutores. A participação foi voluntária. O tamanho da amostra é de 49 indivíduos. Os participantes assinaram um termo de consentimento livre e esclarecido que explica o propósito do questionário, o que é esperado dos participantes e os riscos envolvidos. A assinatura do termo também demonstrava que os participantes estavam ali por livre e espontânea vontade e poderiam se retirar do experimento a qualquer momento. ${ }^{9}$ Além disso, os participantes preencheram uma folha de dados anônimos, na qual informavam o gênero, idade e escolaridade. Dos participantes, 33 são do sexo masculino e 16 do feminino; 24 indivíduos têm idade igual ou inferior a 25 anos, 11 indivíduos entre 25 e 40 anos e 8 indivíduos com 40 anos ou mais..$^{10}$ Quanto à escolaridade, a amostra é composta por 26 graduandos, 13 mestrandos, 7 doutorandos e 3 doutores.

$9 \quad$ O parecer consubstanciado do Comitê de Ética em Pesquisa pode ser encontrado no sítio da Plataforma Brasil (endereço eletrônico:<aplicacao.saude.gov.br/plataformabrasil >), sob o número 427.999

10 Seis indivíduos não responderam sua idade. 
Por se tratar de um experimento em laboratório, sabe-se que existe um viés de seleção. Essa é uma característica desse tipo de experimento. Para tentar diminuir esse tipo de viés, muitos pesquisadores conduzem experimentos de campo. ${ }^{11}$ No entanto, isso não elimina o viés de seleção. Tanto o procedimento de coleta de dados através de participação voluntária quanto o tamanho da amostra utilizados neste trabalho seguem em grande medida as práticas usadas por Kahneman e Tversky (1979), Tversky e Kahneman (1992) e Gonzalez e Wu (1999).

Os participantes não receberam incentivo financeiro. $\mathrm{O}$ fato de não possuir pagamentos ou recompensas traz um viés hipotético (hypothetical bias) ao experimento. Esse viés torna as pessoas menos avessas ao risco do que normalmente seriam se os valores envolvidos nas apostas fossem reais e quando os valores do prêmio são altos (HOLT; LAURY, 2002; KACHELMEIER; SHEBATA, 1992). Holt e Laury (2002) apresentam esse viés em um estudo sobre aversão ao risco e o efeito de incentivos. No entanto, Harrison et al. (2005) mostram que o viés é menor do que inicialmente demonstrado por Holt e Laury (2002), pois o experimento proposto por estes apresentava problemas relativos aos efeitos de ordem. ${ }^{12}$ Loomis (2014) tece comentários sobre estratégias ex ante e ex post para superar o viés hipotético em pesquisas com preferências declaradas. Nesse sentido, como estratégia ex ante, se explicou aos respondentes a importância de serem honestos, as consequências de suas respostas e a garantia de que não haveria respostas corretas. Como estratégia ex post, se usou a data screening, excluindo-se as observações que possuíam resultados absurdos (de acordo com a lógica exposta nos resultados). Maiores detalhes e as implicações desse tipo de viés são discutidos nos resultados e na seção final.

O questionário aplicado consistiu em 45 questões, das quais três foram repetidas com o objetivo de testar consistência e averiguar reversões de preferência. Foram seis pares de valores monetários (200 e 0, 500 e 0, 1000 e 0, 3000 e 0, 500 e 250 , e 3000 e 1000) e sete pares ordenados de probabilidades (0,01 e 0,99; 0,05 e 0,95; 0,1 e 0,9; 0,25 e 0,75; 0,5 e 0,5; 0,75 e 0,25, e 0,01 e 0,99 - a primeira probabilidade associada ao maior valor monetário). A combinação dos valores com as probabilidades totalizou 42 diferentes questões.

Foram realizadas cinco sessões de aplicação dos questionários. O número de participantes em cada sessão variou entre um máximo de 20 e um mínimo de cinco indivíduos. A média do tempo de respostas foi de 16 minutos. Todas as sessões tiveram uma parte introdutória de aproximadamente cinco minutos, na qual os participantes recebiam esclarecimentos e instruções de como responder ao questionário. Além disso, foi enfatizado aos participantes que o objetivo do

\footnotetext{
11 Ver Harrison e List (2004).

12 Essa discussão também pode ser encontrada em Harrison (2005), e uma discussão sobre viés hipotético em experimentos econômicos pode ser encontrada em Harrison (2006).
} 
questionário era descobrir suas preferências, portanto não havia respostas certas nem erradas.

O questionário foi apresentado no programa Excel e continha 45 questões. $\mathrm{O}$ exemplo de uma questão encontra-se no apêndice A. Cada uma mostrava, do lado esquerdo da tela, a respectiva aposta em destaque. Além disso, do lado direito da tela aparecia o seguinte texto para todas as questões: "Indique sua preferência: abaixo se encontra um valor em reais. Considere esse valor como um ganho certo, você tem $100 \%$ de chance de ganhá-lo. Nas células cinza, você deve afirmar sua preferência entre o valor indicado e a aposta ao lado representada pelo gráfico. Após, outro valor irá aparecer abaixo e você deve novamente afirmar sua preferência entre esse novo valor e a aposta ao lado. Aparecerão seis valores. Responda nas células cinza "s" para sim, eu prefiro o ganho certo, ou "n" para não, eu prefiro a aposta. Aperte a tecla enter após cada resposta.".

Para ilustrar a aposta, $(1.000|0,5 ; 0| 0,5)$ indica que há uma probabilidade de $50 \%$ de ganhar $\mathrm{R} \$ 1.000$ e uma probabilidade de $50 \%$ de ganhar $\mathrm{R} \$ 0$ (nada). No questionário, o primeiro valor que o respondente enxergava era a mediana entre os dois resultados envolvidos na aposta, que nesse caso seria $\mathrm{R} \$ 500$. O participante, então, deveria indicar sua preferência na célula ao lado digitando "s" se preferisse o ganho certo da mediana ( $\mathrm{R} \$ 500,00)$, ou "n" se preferisse a aposta. Após essa decisão tomada, um novo valor aparecia abaixo da mediana ( $\mathrm{R} \$ 500,00)$. Esse novo valor era estabelecido de acordo com uma fórmula condicional: se o indivíduo respondesse " $\mathrm{s}$ " para primeira pergunta, a fórmula que definia o próximo valor era $\mathrm{m}_{\mathrm{i}}=\mathrm{m}_{\mathrm{i}-1}-\left[\mathrm{m}_{1} / 2^{\mathrm{i}-1}\right]$, caso respondesse " $\mathrm{n}$ ", o novo valor era definido por $\mathrm{m}_{\mathrm{i}}=\mathrm{m}_{\mathrm{i}-1}+\left[\mathrm{m}_{1} / 2^{\mathrm{i}-1}\right]$, em que $\mathrm{m}_{1}$ é o valor da mediana entre $x$ e $y$ (nesse caso entre 1000 e 0) e i é o número da interação.

Após indicar sua preferência entre os seis valores de ganho certo e a aposta em questão, o equivalente de certeza foi calculado como sendo a mediana entre a última resposta que o indivíduo respondeu "s" e a última na qual ele respondeu "n". Por exemplo, se as respostas de um indivíduo seguissem o Quadro 1 (tendo em mente a aposta $(1.000|0,5 ; 0| 0,5))$, nesse caso o equivalente de certeza desse indivíduo referente à aposta em questão seria $R \$ 398,5$ (a mediana entre $R \$ 406$ e $R \$ 391$ ).

Quadro 1 - Exemplo hipotético de resposta a uma pergunta do questionário

\begin{tabular}{|c|c|}
\hline R\$ 500 & $\mathrm{s}$ \\
\hline $\mathbf{R} \mathbf{2 5 0}$ & $\mathrm{n}$ \\
\hline $\mathbf{R} \mathbf{3 7 5}$ & $\mathrm{n}$ \\
\hline $\mathbf{R} \mathbf{4 3 8}$ & $\mathrm{s}$ \\
\hline $\mathbf{R} \mathbf{4 0 6}$ & $\mathrm{s}$ \\
\hline $\mathbf{R} \mathbf{3 9 1}$ & $\mathrm{n}$ \\
\hline
\end{tabular}

Fonte: Elaboração própria. 
Cada questionário tinha sua ordem aleatória de questões. A sequência aleatória foi criada no programa Matlab: foram criadas 100 sequências aleatórias do número 1 ao 42. Como cada questão correspondia a uma planilha do programa, as sequências aleatórias criadas foram inseridas nos hiperlinks de cada questão. As três questões repetidas foram respondidas sempre após as outras 42 , e foram as mesmas para todos os participantes.

Essa forma de apresentar o questionário minimiza efeitos de ordem (order effects) e possíveis distorções decorrentes de efeitos de escala (scalling effects). Efeitos de ordem, como diz o próprio nome, acontecem em virtude de a ordem de apresentação das questões afetar as respostas dos participantes. $\mathrm{O}$ trabalho de Harrison et al. (2005) mostra que pesquisas de aversão ao risco podem sofrer de efeitos de escala, pois as pessoas poderiam se tornar mais avessas ao risco à medida que os valores envolvidos nas questões são aumentados. Apesar de não provar a existência dos efeitos de escala, o trabalho de Harrison et al. (2005) apresenta significativas evidências de sua existência.

\section{Resultados}

A amostra analisada nesta seção contém 48 participantes. Um participante foi excluído porque respondeu apenas a metade do questionário, uma mulher com idade igual ou inferior a 25 anos e graduanda. Os resultados das estimações individuais podem ser encontrados no Apêndice B.

O número de observações de cada participante não é o mesmo. Algumas respostas não foram incluídas nos dados usados nas regressões devido àquilo que chamamos de absurdos. Esses absurdos aconteceram em apostas nas quais o ganho mínimo era maior que zero. Nessas apostas, os indivíduos se deparavam com escolhas nas quais o ganho certo poderia ser maior que o máximo que a apostaria pagaria, ou menor que o mínimo que a apostaria pagaria. Quando confrontados com essas situações, esperava-se que o comportamento de todos fosse de evitar esses absurdos preferindo o ganho certo quando este estivesse acima dos ganhos da aposta (ou, então, preferindo a aposta quando o ganho certo estivesse abaixo dos valores da aposta). No entanto, isso nem sempre ocorreu. Talvez por desatenção ou erro de digitação, ou ambos, alguns participantes ignoraram ganhos certos maiores que a máxima recompensa da aposta, ou aceitaram ganhos certos menores que a menor recompensa da aposta. Apesar de não ser ideal tal fato acontecer, optou-se por permitir que acontecesse para manter a fórmula que definia os valores de ganho certo igual em todas as questões. Excluíram-se esses absurdos da base dados, pois faziam com que os equivalentes de certeza ficassem fora do intervalo de possíveis ganhos da aposta. Portanto, nem todos os participantes possuem as 42 
observações esperadas. O número de observações de cada participante é encontrado no Apêndice B.

A confiabilidade das respostas em experimentos como esse é checada através das reversões de preferência. Reversões de preferência ocorrem quando, em questões repetidas, o participante inverte sua preferência declarada anteriormente na mesma questão. Stott (2006) afirma que a taxa de reversão de preferências usualmente fica entre $10 \%$ e $30 \%$ na literatura. Neste experimento, como três questões são repetidas, será considerada uma reversão de preferência sempre que o equivalente de certeza da questão repetida indicar que o participante mudou sua atitude em relação ao risco. Com esse critério, a taxa de reversão encontrada foi de $29 \%$.

A Tabela 1 mostra os resultados das estimações. A legenda "amostra" representa a totalidade da amostra, com exceção das exclusões mencionadas anteriormente. Para efeitos de comparação, abaixo encontram-se os resultados de divisões dentro da amostra de acordo com as características das legendas. Essas estimações (de subamostra) devem ser vistas como exploratórias e os resultados devem ser analisados com restrições, visto que o tamanho da amostra dessas divisões é pequeno.

Tabela 1 - Estimação paramétrica a partir da máxima verossimilhança

\begin{tabular}{lccc}
\hline & \multicolumn{3}{c}{ Parâmetros } \\
\cline { 2 - 4 } & $\alpha$ & $\delta$ & $\gamma$ \\
\hline Amostra & $1,06(0,065)$ & $0,57(0,052)$ & $0,33(0,014)$ \\
Homens & $1,14(0,081)$ & $0,58(0,060)$ & $0,39(0,018)$ \\
Mulheres & $0,92(0,109)$ & $0,56(0,097)$ & $0,20(0,021)$ \\
Graduandos & $1,06(0,078)$ & $0,63(0,068)$ & $0,35(0,017)$ \\
Mestrandos & $1,11(0,152)$ & $0,39(0,088)$ & $0,31(0,030)$ \\
Doutorandos & $1,08(0,225)$ & $0,73(0,204)$ & $0,21(0,036)$ \\
Doutores & $0,85(0,079)$ & $0,70(0,089)$ & $0,58(0,036)$ \\
Idade 25 & $1,07(0,090)$ & $0,61(0,076)$ & $0,35(0,019)$ \\
25 < idade $<40$ & $0,94(0,116)$ & $0,42(0,082)$ & $0,28(0,026)$ \\
Idade 40 & $1,18(0,149)$ & $0,63(0,113)$ & $0,34(0,028)$ \\
\hline
\end{tabular}

Fonte: Elaboração própria.

Nota: Desvio padrão entre parênteses.

Os valores dos parâmetros para todos os grupos se encontram dentro do esperado. Os resultados da Tabela 1 são produto da estimação por máxima verossimilhança. Também foi realizada a estimação por mínimos quadrados ordinários não lineares. Como os parâmetros apresentaram valores extremamente similares nos dois métodos, optou-se pelo primeiro em função de menores desvios padrões 
para o parâmetro $\gamma$ e de maior convergência dos parâmetros para as estimações individuais.

Como os valores da Tabela 1 se comparam aos valores encontrados na literatura? Booij, Praag e Kuilen (2010, p. 121, tradução nossa) reúnem em uma tabela a "[...] maioria dos estudos que de alguma forma relataram uma medida paramétrica para a função utilidade, para o coeficiente de aversão à perda, ou para a função ponderação das probabilidades sob a teoria do prospecto”. Nessa tabela, as formas funcionais assumidas para a função utilidade são as da equação 5 utilizada neste estudo. Para a função de ponderação das probabilidades, quatro formas funcionais são utilizadas pelos estudos que compõem a tabela. As formas utilizadas para função de ponderação são as equações 9 e 10 (TVERSKY; KAHNEMAN, 1992), a equação 11 (GOLDSTEIN; EINHORN, 1987) e duas formas introduzidas por Prelec (1998). Os parâmetros estimados foram $\alpha$, no domínio positivo, e $\gamma$ e $\delta$, no domínio positivo e negativo. No domínio positivo que foi estimado neste estudo, o valor de $\alpha$ nos 19 estudos que compõem a Tabela 2 variou entre 0,22 e 1,01. O valor mínimo para $\gamma$ foi de 0,41 e o máximo, de 1,05. Com relação ao parâmetro $\delta$, também no domínio positivo, a variação foi maior, ficando entre 0,65 e 2,12. É importante mencionar que os valores de $\alpha$ e $\gamma$ são mais diretamente comparáveis entre estudos, enquanto o parâmetro $\delta$, por ser ligado à atratividade das apostas, e estas não serem as mesmas em cada estudo, deve ser comparado com mais cuidado.

Analisando-se os dados da tabela de Booij, Praag e Kuilen (2010) e comparando-os com os parâmetros estimados neste estudo, percebe-se que os resultados deste estudo estão ligeiramente fora dos intervalos encontrados em outros estudos. $\mathrm{O}$ valor do parâmetro $\alpha$ encontrado aqui, de 1,06, encontra-se um pouco acima dos valores usualmente estimados, no entanto ainda está de acordo com os resultados mais recentes que indicam o parâmetro como próximo da linearidade. Anteriormente, o trabalho de Fehr-Duda et al. (2006) era o detentor do valor mais alto $(1,01)$ para o parâmetro. Com relação ao parâmetro $\delta$, a literatura mostra uma grande variedade no seu valor, com o máximo, encontrado por Goeree et al. (2002), de 2,12 e o mínimo, encontrado por Adbellaoui (2000), de 0,65. Por falta de referência, é difícil analisar esse parâmetro em termos absolutos, pois o parâmetro reflete a atratividade que os participantes dos experimentos atribuíram às apostas jogadas no experimento no qual participaram e que não são as mesmas. Nesse sentido, o valor encontrado por este estudo, de 0,57, encontra-se um pouco abaixo entre os outros da literatura, indicando que as apostas jogadas nos outros experimentos foram mais atrativas que as jogadas neste estudo. O último parâmetro estimado aqui, $\gamma$, o valor encontrado, de 0,33 , foi o menor encontrado pela literatura, o valor mínimo, anteriormente, de 0,41, pertencia a Donkers, Melenberg e 
Soest (2001). Esse fato mostra que os economistas da PUCRS não são os melhores quando se trata de discriminar as probabilidades.

A tabela de Booij, Praag e Kuilen (2010) traz outras informações interessantes e que mostram que existem algumas escolhas possíveis para esse tipo de experimento, como o estimador a ser utilizado e o tipo de procedimento adotado. Além disso, explicita qual estudo usou incentivos monetários e quais não (11 não usaram incentivos financeiros de pagamento contingente e oito usaram), sendo que os estudos que conseguiram utilizar grandes amostras não usaram incentivos. É possível perceber a grande variação que existe no tamanho das amostras, sendo que o trabalho de Gonzalez e Wu (1999) utiliza uma amostra de 10 participantes, ${ }^{13}$ enquanto que o estudo de Donkers, Melenberg e Soest (2001) utiliza uma amostra de 2.593 pessoas.

Booij, Praag e Kuilen (2010) também calcularam as médias para os parâmetros dos 19 estudos. Os resultados estão na Tabela 2.

Tabela 2 - Média das estimações de dezenove pesquisas

\begin{tabular}{l|c} 
Parâmetro & Média \\
\hline$\alpha$ & 0,69 \\
$\delta^{+}$ & 0,76 \\
$\gamma^{+}$ & 0,69
\end{tabular}

Comparando-se as médias dos parâmetros com os resultados da Tabela 1, percebe-se, neste estudo, um valor maior de $\alpha$ para todos os grupos, um $\delta$ menor para todos os grupos, e um $\gamma$ significativamente menor para todos os grupos, com exceção dos doutores cujos parâmetros se aproximam das médias da Tabela 2.

Uma possível explicação para o alto valor do parâmetro $\alpha$ e o baixo valor do parâmetro $\delta$ é o viés hipotético. Conforme mencionado anteriormente, esse viés faz com que, em virtude das apostas não serem jogadas de verdade, os participantes tornem-se menos avessos ao risco do que realmente seriam se as apostas jogadas envolvessem altos prêmios (HOLT; LAURY, 2002; KACHELMEIER; SHEBATA, 1992). Nesse sentido, o parâmetro ligado à função utilidade e o relacionado à atratividade das apostas podem, hipoteticamente, serem afetados pelo viés, enquanto o parâmetro ligado à discriminabilidade das probabilidades não deveria ser afetado.

Harrison (2007) é um crítico dos experimentos sem incentivos financeiros e comenta sobre o fato de que dentro da economia comportamental se insiste em usar escolhas hipotéticas. No entanto, é preciso contextualizar a crítica e ressaltar

13 Os autores realizaram duas sessões de duas horas cada para aplicar seus questionários aos participantes, pois, como realizaram uma estimação não paramétrica, necessitavam aplicar uma grande quantidade de perguntas. 
que não existe um consenso sobre uma teoria do viés hipotético em pesquisas de preferências declaradas. Com relação à crítica de Harrison (2007), é importante mencionar, ainda, que seus trabalhos investigam a vontade de pagar (willingness-to-pay) dos indivíduos por bens públicos relacionados ao meio ambiente. Portanto, descobrir o valor verdadeiro da vontade de pagar é fundamental nesses casos. Além disso, não existe definição da magnitude para que um valor seja considerado alto e, assim, revelar o viés hipotético. A definição de alto valor pode variar entre indivíduos e não há pesquisa que esclareça se ele estaria ligado à renda, ao patrimônio ou a algum valor de referência local (como salário mínimo ou renda média). Para a economia comportamental, o conhecimento da existência de um viés hipotético e a adoção de medidas para reduzi-lo, como as que tomamos, são suficientes para não invalidar experimentos sem incentivos monetários na forma de pagamento contingente.

Contudo, enfatiza-se que, da mesma forma que quanto mais aleatório é o processo de seleção da amostra menor é a possibilidade de um viés de seleção, pesquisas com altos incentivos monetários ligados a apostas de altos valores (ainda que não esteja clara a magnitude desses altos valores) são muito importantes para comparação de resultados.

Vale ressaltar, também, que os resultados de Holt e Laury (2002) mostrando que as pessoas vão se tornando mais avessas ao risco à medida que os resultados envolvidos nas apostas vão aumentando, fenômeno denominado de efeito de escala, derrubariam as hipóteses de aversão ao risco relativa constante e de aversão ao risco absoluta constante. No entanto, problemas de efeito de ordem colocaram essas conclusões em dúvida.

É interessante notar que todas as pesquisas consideradas na tabela de Booij, Praag e Kuilen (2010) foram realizadas em países desenvolvidos. O único estudo que encontramos para países em desenvolvimento foi o trabalho de Tecles e Resende (2012). Eles estimaram o valor de $\alpha$ usando mínimos quadrados não lineares. Os resultados encontrados para $\alpha$ foram de 0,89 e 0,99 (foi utilizado um método diferente ao deste estudo, sendo usada apenas uma probabilidade para a estimação de cada valor de $\alpha$; as probabilidades utilizadas foram 0,5 e 0,66.). Não foi estimado o valor de $\gamma$ e $\delta$.

Por último, comparou-se a forma da função de ponderação das probabilidades estimadas neste trabalho com a forma resultante das médias presentes na Tabela 2. Dessa forma, a Figura 5 mostra a forma da função utilidade e da função ponderação segundo dados da Tabela 2. No lado A da figura, vê-se a função utilidade nos domínios positivos e negativos, enquanto no lado $b$, a função ponderação das probabilidades também em ambos os domínios. 
Figura 5 - Função utilidade (A) e função ponderação das probabilidades (B) de acordo com as médias da Tabela 3
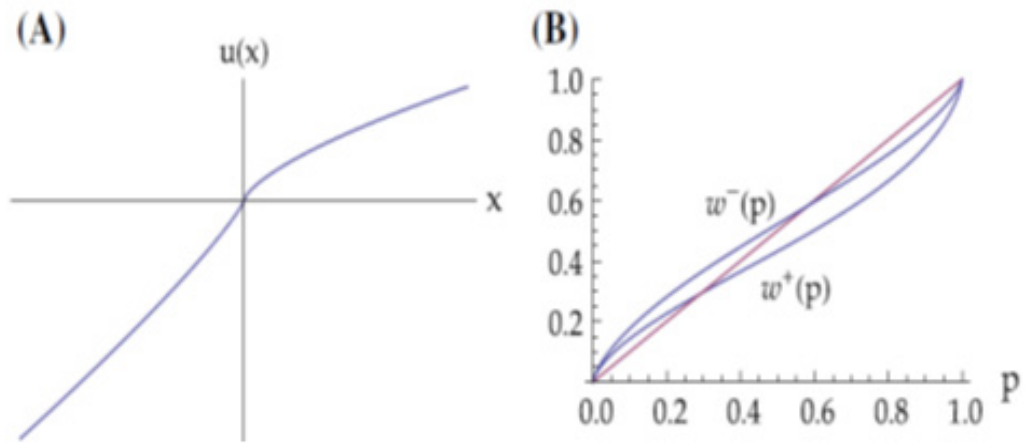

Fonte: Booij, Praag e Kuilen (2010).

A Figura 6 compara a função ponderação das probabilidades entre a amostra da PUCRS e as médias apresentadas na Tabela 2. As diferenças nas funções demonstram a diferença na atratividade entre os dois grupos, representada pela diferença de nível das duas curvas, e a diferença na forma como discriminam as probabilidades, representada pelo formato em "s" mais pronunciado para a amostra aqui estimada. Não foi construído o gráfico de comparação para a função utilidade porque o resultado encontrado seria representado por linha de reta de 45 graus no quadrante 1 . 
Figura 6 - Função ponderação das probabilidades para esta amostra e para a média da literatura

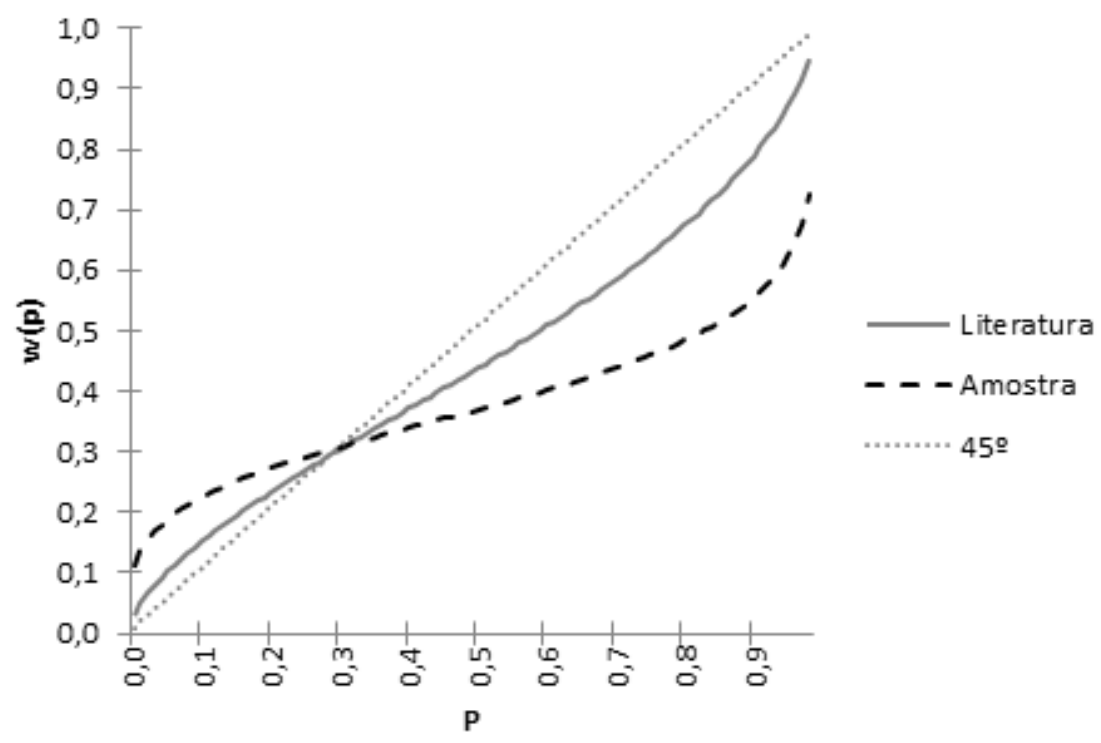

Elaboração própria.

Com a análise desses três parâmetros da amostra, e comparando-os com os resultados já encontrados na literatura, pode-se dizer que, de acordo com os resultados: olhando exclusivamente para o parâmetro da função utilidade $(\alpha)$, os economistas da PUC seriam mais propensos ao risco do que a média encontrada na literatura; observando-se os parâmetros da função de ponderação das probabilidades, percebe-se um valor mais baixo do que o encontrado na literatura para a atratividade das apostas ( $\delta$ ) e um valor mais baixo para a discriminação das probabilidades $(\gamma)$. Enquanto os parâmetros $\alpha$ e $\delta$ são mais subjetivos e requerem cuidado na hora de compará-los entre amostras, o parâmetro $\gamma$ é suficientemente claro, indica quanto a amostra entende e compreende as probabilidades. Dessa forma, os resultados indicam que os economistas da PUCRS possuem maior dificuldade em compreender alterações nas probabilidades envolvidas em eventos incertos. A partir desse ponto, pode-se especular motivos, como, por exemplo, uma maior dificuldade com fundamentos da disciplina de matemática.

A análise dos resultados dos grupos de subamostra, apesar de todas as limitações que carrega, pode ser bastante interessante. Nesse sentido, desenvolveu-se uma extensão dos resultados analisando-se essa subamostra. É primordial enfatizar o caráter exploratório dessa extensão. No entanto, os insights dela decorrentes parecem ser promissores e podem ser vistos como um indicativo de trilha para pesquisas futuras na área. 


\subsection{Extensão}

Esta é uma extensão exploratória envolvendo os dados coletados e estimados, dividindo a amostra total em grupos de análise menores. Dessa forma, foi possível explorar se existiriam diferenças nos parâmetros entre diferentes gêneros, diferentes idades e diferentes escolaridades. O pequeno tamanho das subamostras e o fato de não serem balanceadas comprometem a possibilidade de uma análise mais assertiva sobre os resultados. Esperamos que a extensão apresentada possa servir como ponto de partida para estudos mais aprofundados sobre o tema.

Para uma análise mais detalhada, para cada um dos critérios de divisão da amostra - gênero, escolaridade e faixa etária -, foram construídos gráficos que classificam a resposta dos grupos separadamente para cada uma das 42 questões respondidas. As Figuras 7, 9 e 11 apresentam esses gráficos e as Tabelas 3, 4 e 5 trazem as porcentagens dos grupos de acordo com seu tipo de comportamento.

Antes de se analisar os resultados nos gráficos é importante notar que a generalização do padrão quaternário de atitudes em relação ao risco descoberto por Tversky e Kahneman (1992) está presente em todos os grupos e é a característica mais evidente que os permeia (na verdade o padrão aqui é binário, pois não se analisou o comportamento dos participantes com relação a perdas). Cabe lembrar que o padrão afirma que, para ganhos, as pessoas tendem a ser amantes do risco para pequenas probabilidades e avessas ao risco para médias e grandes probabilidades. Observa-se que as apostas estão organizadas começando pela menor probabilidade $(0,01)$ de ocorrer o maior resultado, e que a busca pelo risco acontece até a probabilidade 0,25 , enquanto que a partir da probabilidade 0,5 todos os grupos tornam-se predominantemente avessos ao risco, independes das magnitudes dos resultados.

Voltando à análise da Tabela 1 , ao se observar o parâmetro $\delta$, que representa a atratividade dos indivíduos em relação às apostas questionadas, percebe-se, à primeira vista, que os parâmetros de todos os grupos são diferentes. Porém, quando se analisa estatisticamente se os parâmetros são diferentes, as conclusões mudam. Para averiguar se as diferenças são estatisticamente significativas, foi construído um teste-z. Dessa forma, a análise por gênero indica que as mulheres acharam as apostas menos atrativas que os homens, no entanto, o teste-z construído apontou que não há diferença estatisticamente significativa entre os parâmetros (todos os valores dos testes-z, assim como seus respectivos p-valores, estão no Apêndice C). Com relação ao nível de escolaridade, destaca-se a diferença significativa na atratividade das apostas entre os grupos graduandos-mestrandos e mestrandos-doutores. Entretanto, não há diferença estatística quando a comparação se dá entre graduandos-doutorandos, graduandos-doutores, mestrandos-doutorandos e doutorandos-doutores. Por último, analisando-se a amostra pelas faixas etárias, 
conclui-se que há diferença significativa entre aqueles com idade menor ou igual a 25 anos em relação aos entre 25 e 40 anos. Todos os outros parâmetros $\delta$ não são significativamente diferentes entre si. Portanto, a atratividade das apostas não apresenta um padrão de comportamento, não se mostrando nem crescente nem decrescente de acordo com escolaridade ou idade, mas com diferenças pontuais entre os grupos pesquisados.

A análise do parâmetro $\gamma$, ligado à discriminabilidade das probabilidades, apresenta uma foto diferente da análise por atratividade. A análise estatística dos dados (testes-z) mostra que: o parâmetro $\gamma$ dos homens é significativamente diferente das mulheres; com relação à escolaridade, todos os grupos são estatisticamente diferentes entre si, com exceção de graduandos-mestrandos. Com relação às idades, há diferença significativa apenas entre os grupos idade $\leq 25-25<$ idade $<40$ e não há diferença entre idade $\leq 25$ - idade $\geq 40$ e $25<$ idade $<40$-idade $\geq$ 40. Dessa forma, a análise por discriminabilidade das probabilidades parece trazer um maior impacto para explicar as diferenças de comportamento. Vale notar, entretanto, que a tendência não segue um comportamento esperado, principalmente no que diz respeito à escolaridade, sendo decrescente na maior parte e, ao final, saltando para o maior valor de $\gamma$ dos doutores.

Por último, com relação ao parâmetro $\alpha$, a única diferença significativa foi entre os graduandos e os doutores. Todos os outros grupos de gênero, escolaridade ou idade não apresentaram diferença estatisticamente significativa entre si.

\subsection{Gênero}

A Figura 7 apresenta classificação de comportamento em relação ao risco para a amostra e para os grupos de gênero de acordo com as medianas dos equivalentes de certeza de cada aposta e de cada grupo. ${ }^{14}$ As apostas estão organizadas da menor probabilidade, combinada com o maior resultado da aposta, para a maior probabilidade. ${ }^{15}$

14 Por exemplo, foram selecionados os homens da amostra e observadas suas respostas referentes à questão 1 . De acordo com o resultado da mediana das respostas foi possível compará-lo com o valor esperado da aposta e observar se o comportamento do grupo para essa aposta foi de busca, neutralidade ou aversão ao risco. Dessa forma, os triângulos presentes da aposta 1 até a 20, na Figura 7, indicam que em todas essas questões os homens apresentaram comportamento de busca pelo risco. As medianas exatas dos equivalentes de certeza para cada aposta podem ser encontradas no Apêndice D.

15 As apostas de 1 a 6 correspondem às probabilidades 0,01 e 0,99 relacionadas, respectivamente, com os resultados: 200 ou 0; 500 ou $0 ; 1000$ ou $0 ; 3000$ ou $0 ; 500$ ou 250; 3000 ou 1000 . As apostas 7 até 12 correspondem às probabilidades 0,05 e 0,95 e seguem a mesma sequência de resultados. A numeração exata das apostas está no Apêndice D. 
Figura 7 - Classificação do comportamento perante o risco da amostra e dos grupos de gênero de acordo com as medianas dos equivalentes de certeza de cada aposta

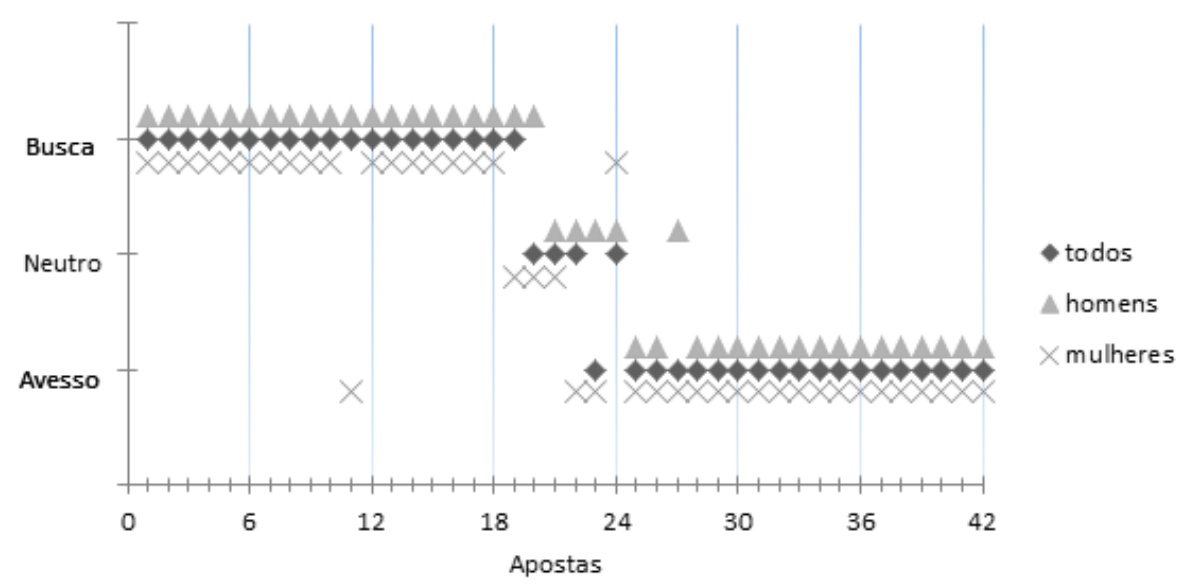

Nota: O eixo vertical é um eixo qualitativo. O fato de a resposta de um grupo aparecer acima de outro dentro da mesma classificação não tem significado (a figura apenas mostra que ambos recebem a mesma classificação; as linhas verticais nos números múltiplos de seis indicam que, a partir da próxima aposta, as probabilidades se alteram).

Observando-se a Figura 7 é possível notar claro padrão de comportamento. As apostas que envolvem probabilidades menores de ganho revelam um comportamento de busca pelo risco. Entre as apostas 19 e 24, o comportamento que prevalece é de neutralidade. De acordo com a numeração das apostas, é possível observar que as mulheres começam a apresentar comportamento de neutralidade e de aversão ao risco antes do que os homens. No restante, da aposta 25 em diante, que envolvem probabilidades médias e grandes, o comportamento é majoritariamente de aversão ao risco.

Analisando-se o percentual por tipo de resposta de cada grupo na Tabela 3, percebe-se que as mulheres apresentam um comportamento mais avesso ao risco que os homens, enquanto o total da amostra apresenta-se neutro em relação ao risco.

Tabela 3 - Porcentagem de acordo com o tipo de escolha

\begin{tabular}{cccc}
\hline Tipo de escolha & Amostra & Homens & Mulheres \\
\hline Busca pelo risco & $45,2 \%$ & $47,6 \%$ & $42,9 \%$ \\
Aversão ao risco & $45,2 \%$ & $40,45 \%$ & $50,0 \%$ \\
Neutras & $9,5 \%$ & $11,9 \%$ & $7,1 \%$ \\
\hline
\end{tabular}

Fonte: Elaboração própria. 
Havendo as mulheres apresentado comportamento mais avesso ao risco do que os homens, o que poderia explicar esse comportamento? Os resultados da Tabela 1 podem trazer alguma luz sobre essa diferença. Como foi visto, os homens apresentaram diferença estatisticamente significativa no parâmetro ligado à discriminabilidade, em relação às mulheres, e não apresentaram diferença significativa no parâmetro ligado à atratividade das apostas e ao parâmetro $\alpha$. Dessa forma, de acordo com as variáveis analisadas, pode-se dizer que as mulheres se mostraram mais avessas ao risco em relação aos homens porque discriminaram menos as probabilidades. Evidentemente, essa é uma sugestão e não esgota as razões possíveis para essa diferença.

A Figura 8 mostra a diferença da função ponderação das probabilidades de homens e mulheres. Observe que a função masculina está mais próxima da linha de 45 graus do que a função feminina, isso acontece em razão do maior parâmetro ligado à discriminabilidade dos homens. É interessante notar que, mesmo com um valor de $\delta$ menor do que o dos homens, a função das mulheres corta a linha de 45 graus acima da função dos homens devido ao pronunciado grau de curvatura $(\gamma)$ de sua função.

Figura 8 - Função ponderação das probabilidades por gênero

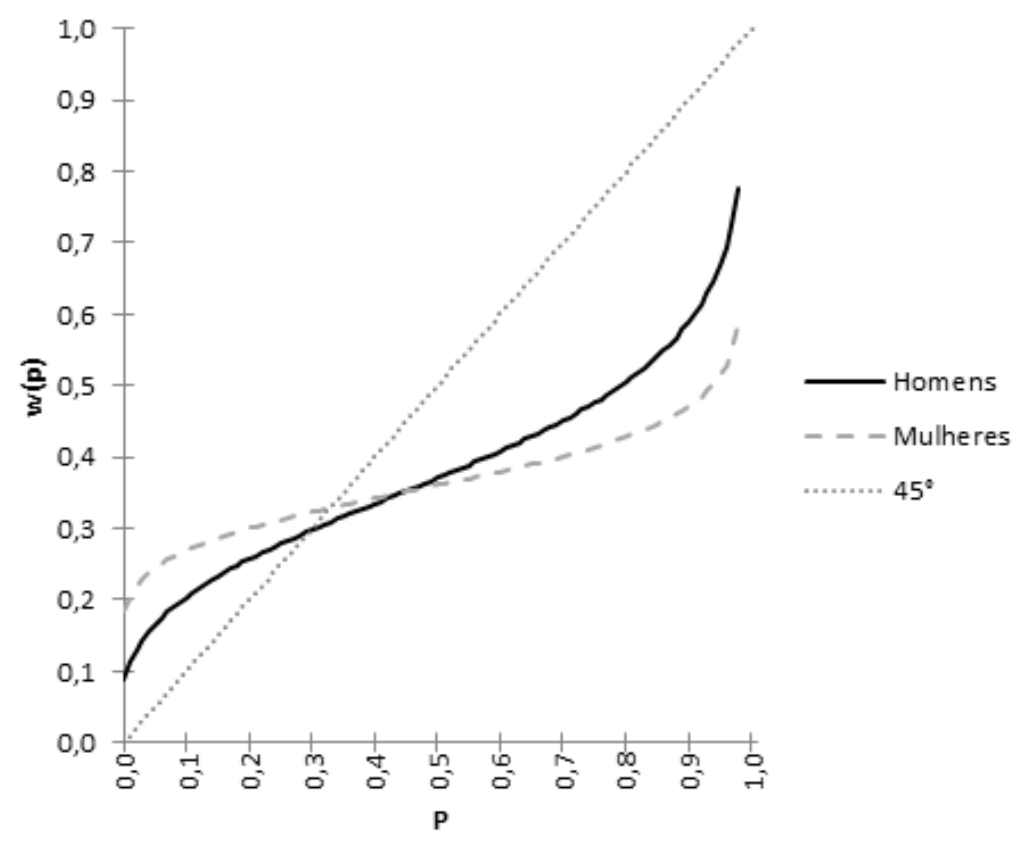

Fonte: Elaboração própria. 


\subsection{Escolaridade}

Observando-se a distribuição das medianas dos equivalentes de certeza das apostas por escolaridade entre busca, neutralidade ou aversão ao risco na Figura 9, nota-se o mesmo padrão de comportamento geral que a análise anterior: para pequenas probabilidades, há predomínio de busca pelo risco, enquanto para médias e grandes probabilidades há maior aversão ao risco. Em relação aos grupos, vê-se que os graduandos continuam buscando o risco em apostas que os mestrandos e doutores, principalmente, já se tornaram avessos ao risco. Nesse sentido, os graduandos apresentam um comportamento de busca pelo risco até a aposta $24 \mathrm{e}$, a partir da aposta 28 , tornam-se, predominantemente, avessos ao risco. Os grupos mestrandos e doutores, no entanto, buscam o risco até a aposta 18 e a partir da aposta 20 são majoritariamente avessos ao risco. Os doutorandos apresentam um comportamento intermediário entre graduandos e mestrandos-doutores, sendo propensos aos riscos até a aposta 22 e tornando-se avessos ao risco da aposta 23 em diante.

Figura 9 - Classificação do comportamento perante o risco dos grupos de escolaridade de acordo com as medianas dos equivalentes de certeza de cada aposta

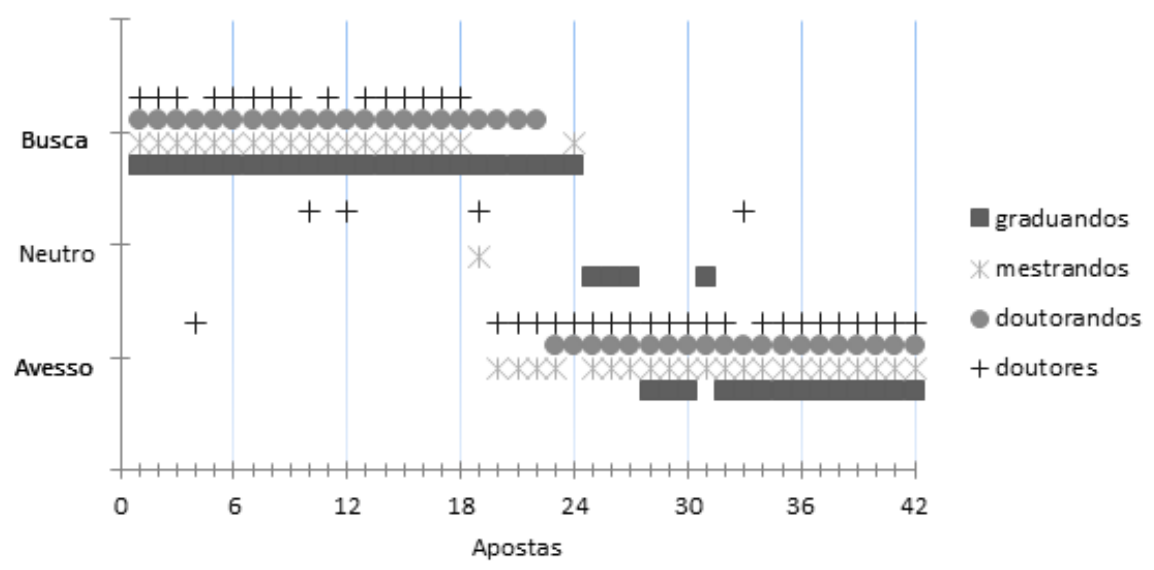

Fonte: Elaboração própria.

Nota: $\mathrm{O}$ eixo vertical é um eixo qualitativo. O fato de a resposta de um grupo aparecer acima da de outro dentro da mesma classificação não tem significado (a figura apenas mostra que ambos recebem a mesma classificação; as linhas verticais nos números múltiplos de seis indicam que a partir da próxima aposta as probabilidades se alteram).

Quando se olha a porcentagem dos grupos por tipo de escolha, na Tabela 4, fica claro que os graduandos apresentam o maior percentual de escolhas de busca 
pelo risco e os mestrandos e doutores, os maiores percentuais relacionados à aversão ao risco. No entanto, percebe-se que não existe um comportamento gradativo no qual a busca ou aversão ao risco vai tornando-se maior ou menor de acordo com o aumento da escolaridade. Os graduandos apresentam um comportamento de oposição aos doutores, enquanto os mestrandos e doutorandos apresentam um comportamento mais heterogêneo, ora se assimilando com os graduandos ora com os doutores. De acordo com os testes-z, essas diferenças de comportamento entre escolaridades são explicadas pela diferença significativa no parâmetro $\alpha$ entre graduandos-doutores, no parâmetro $\delta$ pela diferença entre graduandos-mestrandos e mestrandos-doutores, e no parâmetro $\gamma$ pela diferença significativa entre todos os grupos, com exceção dos graduandos-mestrandos. Dessa forma, a diferença de comportamento relacionada à escolaridade parece ser melhor explicada pela diferente discriminabilidade das probabilidades por cada grupo, visto que o parâmetro $(\gamma)$ ligado a essa característica é o que mais apresentou significativas diferenças entre os valores do parâmetro, e não apenas diferenças pontuais como os outros dois parâmetros ( $\alpha$ e $\delta$ ).

Tabela 4 - Porcentagem de acordo com o tipo de escolha

\begin{tabular}{lcccc}
\hline Tipo de escolha & Graduandos & Mestrandos & Doutorandos & Doutores \\
\hline Busca pelo risco & $57,1 \%$ & $45,2 \%$ & $52,4 \%$ & $35,7 \%$ \\
Aversão ao risco & $33,3 \%$ & $52,4 \%$ & $47,6 \%$ & $54,8 \%$ \\
Neutras & $9,5 \%$ & $2,4 \%$ & $0 \%$ & $9,5 \%$ \\
\hline
\end{tabular}

Fonte: Elaboração própria.

A Figura 10 apresenta os desenhos das funções para os grupos. Nela se percebe como a função dos doutores se aproxima mais da linha de 45 graus do que os outros níveis de escolaridade, representando uma maior discriminabilidade das probabilidades desse grupo. Com relação à atratividade das apostas, a Figura 10 demonstra que os doutorandos foram os que consideraram as apostas mais atrativas e os mestrandos foram os que consideraram menos atrativas. As funções dos graduandos e doutores cortam a linha de 45 graus em lugares próximos. No entanto, observando-se os valores do parâmetro $\delta$ (Tabela 1), nota-se que os valores entre doutores e doutorandos são mais próximos do que os valores entre doutores e graduandos. Como no caso entre gêneros, o grau de curvatura da função dos doutorandos (baixo valor de $\gamma$ ) é o que faz sua função cortar a linha de 45 graus em um ponto mais alto. 
Fugira 10 - Função ponderação das probabilidades por escolaridade

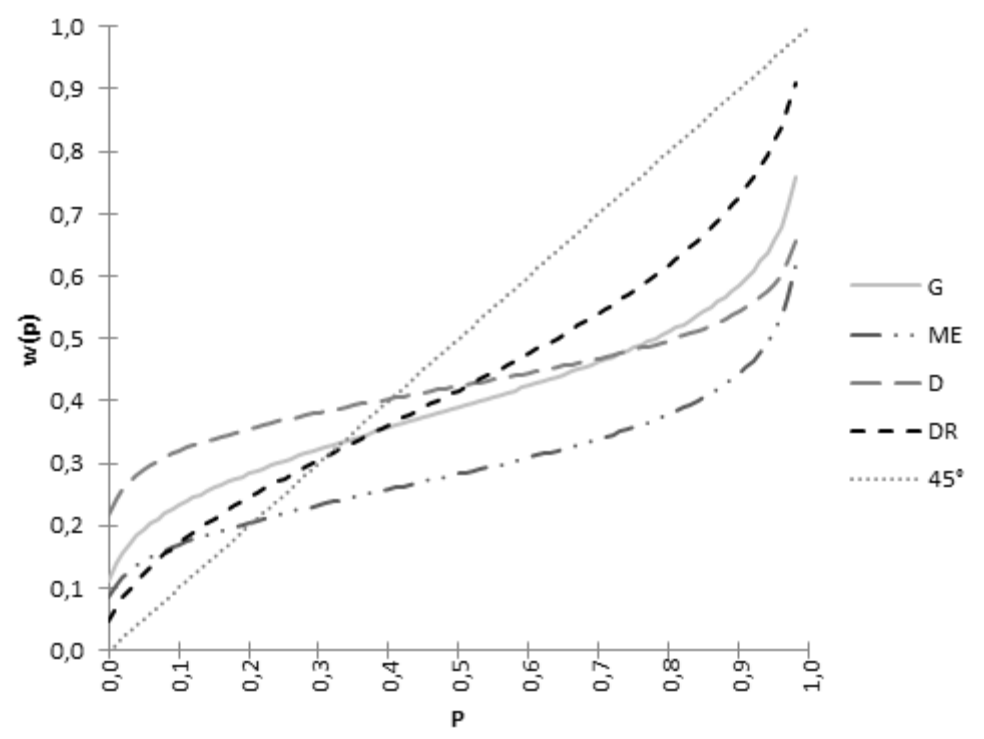

Fonte: Elaboração própria.

\section{4 ldade}

As medianas dos equivalentes de certeza das apostas por idade apresentam o mesmo comportamento observado para os grupos gênero e escolaridade, que confirmam o padrão quaternário - busca pelo risco para pequenas probabilidades e aversão ao risco para médias e grandes probabilidades. Além disso, na Figura 11, percebe-se que o grupo com idade igual ou inferior a 25 anos apresentou busca pelo risco até a aposta 20, entre as apostas 21 e 27 uma mistura de neutralidade e aversão ao risco e apenas a partir da aposta 28 um comportamento avesso ao risco. Aqueles com idade entre 25 e 40 anos apresentaram a maior aversão ao risco, adotando esse comportamento a partir da aposta 20. Já o grupo com idade maior ou igual a 40 anos se mostrou levemente mais propenso ao risco, adotando esse comportamento até a aposta 21 e um comportamento de aversão ao risco a partir da aposta 23. 
Figura 11 - Classificação do comportamento perante o risco dos grupos de idade de acordo com as medianas dos equivalentes de certeza de cada aposta

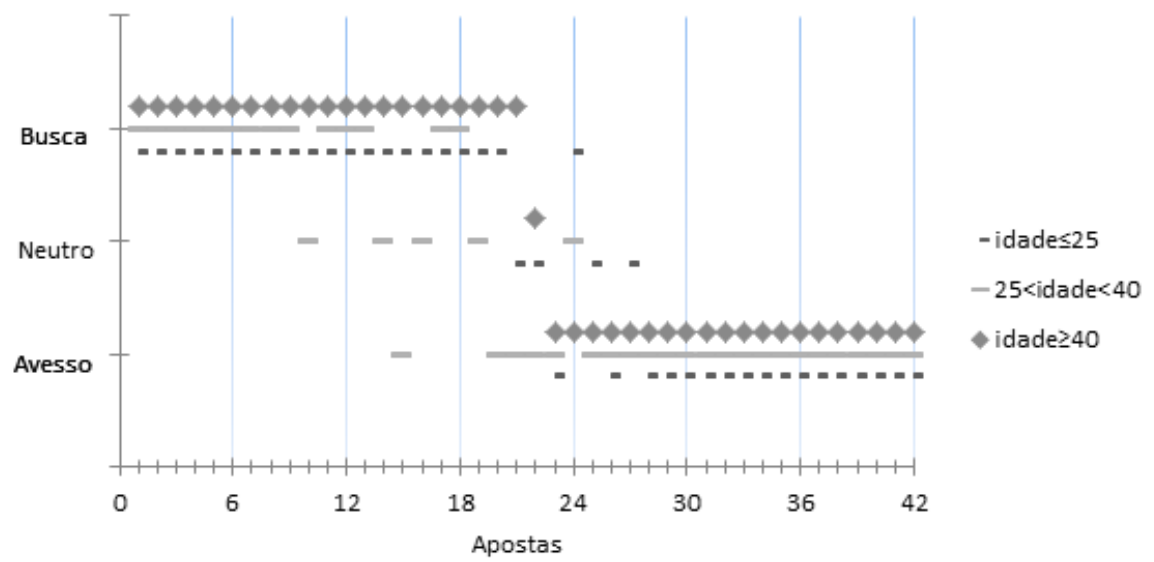

Fonte: Elaboração própria.

Nota: O eixo vertical é qualitativo. O fato de a resposta de um grupo aparecer acima da de outro dentro da mesma classificação não tem significado (a figura apenas mostra que ambos recebem a mesma classificação; as linhas verticais nos números múltiplos de seis indicam que, a partir da próxima aposta, as probabilidades se alteram).

A Tabela 5 mostra o percentual de acordo com o tipo de escolha. A análise por idade parece ser a que menos apresenta um padrão de comportamento entre seus grupos, mostrando-se difícil de extrair uma conclusão dos seus resultados. Tanto a busca quanto a aversão ao risco não evidenciam uma tendência. Além disso, os testes-z apontaram diferença apenas entre idade $\leq 25-25<$ idade $<$ 40 para os parâmetros $\delta$ e $\gamma$, sendo que os mais novos discriminaram melhor as probabilidades.

Tabela 5 - Porcentagem de acordo com o tipo de escolha

\begin{tabular}{cccc}
\hline Tipo de escolha & Idade $\leq \mathbf{2 5}$ & $\mathbf{2 5}<$ Idade $<\mathbf{4 0}$ & Idade $\geq \mathbf{4 0}$ \\
\hline Busca pelo risco & $50 \%$ & $33,3 \%$ & $50 \%$ \\
Aversão ao risco & $40,5 \%$ & $54,8 \%$ & $47,6 \%$ \\
Neutras & $9,5 \%$ & $11,9 \%$ & $2,4 \%$ \\
\hline
\end{tabular}

Fonte: Elaboração própria.

A Figura 12 mostra a semelhança entre o desenho da função de ponderação das probabilidades para os maiores de 40 anos e os menores de 25 anos e a menor atratividade e discriminabilidade dos participantes entre 25 e 40 anos com relação aos outros grupos. 
Figura 12 - Função ponderação das probabilidades por idade

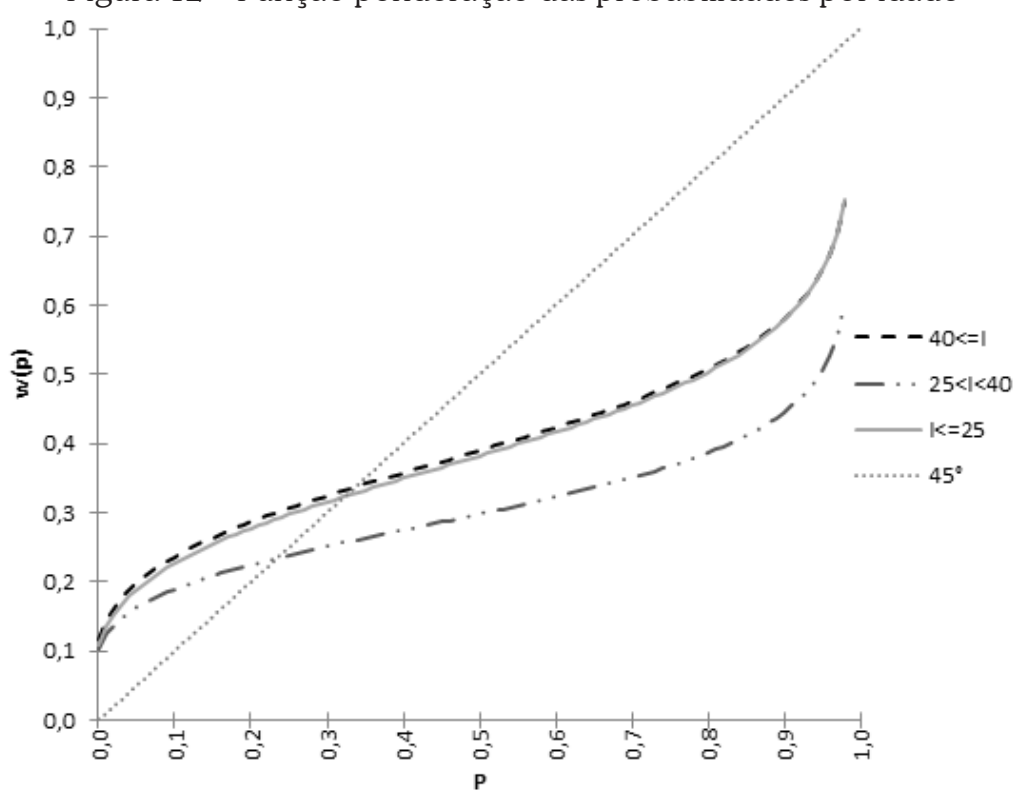

Fonte: Elaboração própria.

A análise demográfica traz algumas evidências que vão de encontro ao que existe na literatura e alguns insights novos. Ela confirma a maior aversão ao risco do gênero feminino e adiciona que esse resultado é decorrente de uma menor discriminabilidade das probabilidades por parte das mulheres. Além disso, a análise por escolaridade indica que altíssimos níveis de escolaridade afetariam o comportamento, tornando as pessoas mais avessas ao risco em virtude de um melhor entendimento das probabilidades. Por último, a análise por idade não revelou nenhuma característica evidente.

Dessa forma, a análise demográfica leva a concluir que diferenças de comportamento existentes entre grupos seriam em razão da diferença de discriminabilidade das probabilidades, pois esse parâmetro apresentou diferenças estatísticas significativas entre os grupos de uma forma mais ampla, e não apenas pontual como os parâmetros ligados à função utilidade e à atratividade das apostas.

Portanto, com base nos resultados deste trabalho, pode-se esperar que, quanto maior o número de mulheres e maior a escolaridade, maior a aversão ao risco esperada. O curioso é notar que essa maior aversão ao risco decorreria pelo mesmo motivo, a discriminabilidade das probabilidades, mas de magnitude contrária, uma menor discriminabilidade por parte das mulheres e uma maior, por parte do altíssimo nível de escolaridade. 


\section{Considerações Finais}

A TUE reinou durante muitos anos como o modelo que descrevia o comportamento de escolha sob risco, apesar das críticas que o modelo sofria. A TP e sua versão cumulativa surgiram como parte da união da psicologia com a economia, combinação que se constitui na base da economia comportamental. Apesar desse debate ser relativamente novo, muito já foi discutido sobre o tema e importantes e sólidos avanços foram feitos. A nova teoria trouxe esclarecimentos, mas também novas questões.

Este estudo tenta contribuir com a teoria realizando um experimento que traz uma metodologia parcialmente nova e que tenta aprimorar a minimização de alguns vieses. Os resultados encontrados mostram que os economistas da PUCRS apresentam um comportamento distinto da média encontrada na literatura econômica, mas nem por isso seria considerado um comportamento atípico. Além disso, este estudo, principalmente sua extensão, traz evidências que servem de inspiração para futuras pesquisas.

A aparente linearidade apresentada pelas funções de utilidades dos grupos não é indicativo definitivo de neutralidade em relação ao risco, pois como Chateauneuf e Cohen (1994) mostram, na TP um indivíduo pode ter função utilidade côncava/convexa e ser amante/avesso ao risco. O que define o comportamento diante do risco do indivíduo é uma combinação entre os parâmetros da função utilidade com os parâmetros da função de ponderação, e não apenas a concavidade ou convexidade da função utilidade, como na TUE.

Alguns estudos semelhantes coletaram informações demográficas e sobre nível acadêmico de seus participantes para averiguar possíveis padrões de comportamento. Na grande maioria desses estudos, a análise demográfica dos resultados não era seu objetivo principal. Booij, Praag e Kuilen (2010) encontram evidências que sugerem que as diferenças entre gênero de comportamento sob risco decorrem de mudanças na elevação da função de ponderação das probabilidades. Essa é uma explicação alternativa àquela encontrada na literatura, que atribui a diferença entre gêneros a dissimilaridades na curvatura da utilidade. Esses resultados são consistentes com os encontrados por Fehr-Duda, Gennaro e Schubert (2006), que obtiveram diferenças significativas no parâmetro ligado à elevação da função de ponderação para ganhos, mas não para perdas. No entanto, Booij, Praag e Kuilen não encontraram diferença na curvatura da função, enquanto Fehr-Duda, Gennaro e Schubert encontraram diferenças significativas entre homens e mulheres. Holt e Laury (2002) encontraram, como neste estudo, que homens são menos avessos ao risco que mulheres - assim como no estudo de Eckel et al. (1998) -, porém esse efeito de gênero desaparece nos tratamentos com altos valores envolvidos nas apostas. Com relação à educação, Booij, Praag e Kuilen (2010) afirmam 
que surpreendentemente não há em seus resultados associações entre nível de escolaridade e diferenças nas funções utilidade ou ponderação. Holt e Laury (2002) também não encontram correlação entre as funções relacionada nem à educação nem à faixa etária. Um ponto em que os trabalhos de Booij, Praag e Kuilen e de Holt e Laury concordam é relacionado à renda dos participantes: nos dois estudos, a renda teve um efeito levemente negativo sobre a aversão ao risco. Esse é um ponto que parece ser promissor para novas pesquisas: analisar o efeito do patrimônio sobre o comportamento dos indivíduos.

A contribuição deste estudo para essa discussão foi confirmar, mais uma vez, a maior aversão ao risco pelo gênero feminino e também relacionar o nível de escolaridade a níveis maiores de aversão ao risco. Nos dois casos, essa maior aversão ao risco seria resultante das diferenças no entendimento das probabilidades. Além disso, sobre esse tema, este estudo é um dos pioneiros para países em desenvolvimento.

É importante frisar que as conclusões apresentadas não pretendem ser a palavra final sobre o assunto; são evidências que apontam para uma direção. Outros estudos que levem em conta outras premissas e metodologias podem chegar a conclusões diversas. A existência do viés hipotético pode alterar resultados e deve ser levado em consideração. Será que só devem ser válidas pesquisas com incentivos monetários na forma de pagamento contingente que reforce o comprometimento dos participantes? Acredita-se que não. A diferença nos resultados para efeito de comparação é importante para a economia comportamental. Além disso, considera-se que se comprove que efeitos de escala (fato que altera o tamanho da aversão/busca pelo risco em decorrência da escala da aposta) afetem as pessoas. Nesse caso, a aversão ao risco de um indivíduo não seria constante, pois aumentaria à medida que os valores envolvidos aumentassem, negando a existência de uma aversão ao risco relativa constante e uma aversão ao risco absoluta constante. Portanto, o efeito escala impõe aos experimentos com pagamento contingente um problema bastante similar ao causado pelo viés hipotético.

Adicionalmente, este trabalho desenvolveu uma nova metodologia de questionário para coletar os equivalentes de certeza necessários à estimação. A nova metodologia reduziu o tempo necessário para responder ao questionário, diminuindo o fardo cognitivo dos participantes. A metodologia também permitiu minimizar possíveis efeitos de ordem e efeitos de escala. Pelo lado negativo, a nova metodologia diminui a confiabilidade das respostas e a torna mais difícil de ser averiguada, pois não é possível aplicar o método usual de verificação de reversões de preferência. A forma usual de checagem de reversões de preferência implica comparar cada resposta das perguntas repetidas aos participantes com suas primeiras respostas. No entanto, no método aplicado neste trabalho, no qual seis 
perguntas foram encadeadas em sequência, uma parte da questão (a mediana que indicava o ganho certo) dependia da resposta à pergunta anterior, ser "s" ou "n". Portanto, uma resposta diferente na primeira pergunta, uma reversão de preferência, levaria automaticamente à reversão de preferência das próximas cinco perguntas.

Por último, com esta pesquisa espera-se ter contribuído para aumentar o debate sobre a economia comportamental no Brasil, um campo de estudo atual e promissor.

\section{Referências}

ABDELLAOUI, M. Parameter-free elicitation of utilities and probability weighting functions. Management Science, v. 46, p. 1497-1512, 2000.

; BLEICHRODT, H.; L'HARIDON, O. A tractable method to measure utility and loss aversion under prospect theory. Journal of Risk and Uncertainty, v. 36, p. 245-266, 2008.

; _ _ _ PARASCHIV, C. Loss aversion under prospect theory: a parameter-free measurement. Management Science, v. 50, n. 10, p. 1659-1674, 2007.

; VOSSMAN, F.; WEBER, M. Choice-based elicitation and decomposition of decision weights for gains and losses under uncertainty. Management Science, v. 51, p. 1384-1399, 2005.

ALLAIS, M. Le comportement de l'homme rationnel devant le risque: critique des postulats and axioms de l'Ecole Americaine. Econometrica, v. 21, p. 503-546, 1953.

ANDERSEN, S.; HARRISON, G. W.; RUTSTRÖM, E. E. Dynamic choice behavior: asset integration and natural reference points. Department of Economics, University of Central Florida, 2006. (Working paper, 06-07, 2006).

BLEICHRODT, H.; PINTO, J. L. A parameter-free elicitation of the probability weighting function in medical decision analysis. Management Science, v. 46, p. 1485-1496, 2002.

BOOIJ, A. S.; PRAAG, B. M. S.; KUILEN, G. A parametric analysis of prospect theory's functionals for the general population. Theory and Decision, v. 68, p. 115-148, 2010.

CAMERER, C. F.; HO, T. Nonlinear weighting of probabilities and violations of the betweenness axiom. Journal of Risk and Uncertainty, v. 8, p. 167-196, 1994.

CHATEAUNEUF, A.; COHEN, M. Risk seeking with diminishing marginal utility in a nonexpected utility model. Journal of Risk and Uncertainty, v. 9, p. 77-91, 1994.

DONKERS, A. C. D.; MELENBERG, B.; SOEST, A. H. O. V. Estimating risk attitudes using lotteries: a large sample approach. Journal of Risk and Uncertainty, v. 22, p. 165-195, 2001.

ECKEL, C. et al. Playing it safe: gender differences in risk aversion. Chicago, 1998. Working Paper presented at the Allied Social Science Association Annual Meetings (CSWEP Sessions). 
ETCHART-VICENT, N. Is probability weighting sensitive to the magnitude of consequences. Journal of Risk and Uncertainty, v. 22, p. 217-235, 2004.

FEHR-DUDA, H.; GENNARO, M.; SCHUBERT, R. Gender, financial risk, and probability weights. Theory and Decision, v. 60, p. 283-313, 2006.

FENNEMA, H.; VAN ASSEN, M. Measuring the utility of losses by means of the tradeoff method. Journal of Risk and Uncertainty, v. 17, p. 277-295, 1998.

GOERRE, J. K.; HOLT, C. A.; PALFREY, T. R. Quantal response equilibrium and overbidding in private-value auctions. Journal of Economic Theory, v. 104, p. 247-272, 2002.

GOLDSTEIN, W. M.; EINHORN, H. J. Expression theory and the preference reversal phenomena. Psychological Review, v. 94, p. 236-254, 1987.

GONZALEZ, R.; WU, G. On the shape of the probability weighting function. Cognitive Psychology, v. 38, p. 129-166, 1999.

HARRISON, G. W. Experimental evidence on alternative environmental valuation methods. Environmental and Resources Economics, v. 34, p. 125-162, 2006.

. Hypothetical bias over uncertain outcomes. In: LIST, J. A. (Ed.). Using experimental methods in environmental and resources economics. Cheltenham, UK: Edward Elgar Pub, 2007.

HARRISON, G. W. et al. Risk aversion and incentive effects: comment. The American Economic Review, v. 95, n. 3, p. 897-901, 2005.

HARRISON, G. W.; LIST, J. A. Field experiments. Journal of Economic Literature, v. 42, n. 4, p. 1009-1055, 2004.

HARRISON, G. W.; RUTSTRÖM, E. E. Expected utility theory and prospect theory: one wedding and a decent funeral. Experimental Economics, v. 12, n. 2, p. 133-158, 2009.

HOLT, C. A.; LAURY, S. K. Risk aversion and incentive effects. The American Economic Review, v. 92, n. 5, p. 1644-1655, 2002.

KACHELMEIER, S. J.; SHEHATA, M. Examining risk preferences under high monetary incentives: experimental evidence from the people's Republic of China. The American Economic Review, v. 82, n. 5, p. 1120-1141, 1992.

KAHNEMAN, D.; TVERSKY, A. Prospect theory: an analysis of decision under risk. Econometrica, v. 47, n. 2, p. 263-291, 1979.

LIST, J. A. Neoclassical theory versus prospect theory: evidence from the marketplace. Econometrica, v. 72, p. 615-625, 2004.

LOOMIS, J. B. Strategies for overcoming hypothetical bias in stated preference surveys. Journal of Agricultural and Resource Economics, v. 39, n. 1, p. 34-46, 2014.

PRELEC, D. The probability weighting function. Econometrica, v. 66, p. 497-527, 1998. 
QUIGGIN, J. A theory of anticipated utility. Journal of Economic Behavior and Organization, v. 3, n. 4, p. 323-343, 1982.

SCHMIDT, U.; TRAUB, S. An experimental test of loss aversion. Journal of Risk and Uncertainty, v. 25, p. 233-249, 2002.

STARMER, C. Developments in non-expected utility theory: the hunt for a descriptive theory of choice under risk. Journal of Economic Literature, v. 38, n. 2, p. 332-382, 2000.

; SUGDEN, R. Violations of the independence axiom in common ratio problems: an experimental test of some competing hypotheses. Annals of Operational Research, v. 19, p. 79-102, 1989.

STOTT, H. Cumulative prospect theory's functional menagerie. Journal of Risk and Uncertainty, v. 32, p. 101-130, 2006.

TECLES, P. L.; RESENDE, G. L. Estimação paramétrica da utilidade sob a teoria do prospecto. 2012. 66 f. Dissertação (Mestrado em Economia) - Departamento de Economia, Universidade de Brasília, Brasília, 2012.

TVERSKY, A.; FOX, C. R. Weighting risk and uncertainty. Psychological Review, v. 102, p. 269-283, 1995.

; KAHNEMAN, D. Advances in prospect theory: cumulative representation of uncertainty. Journal of Risk and Uncertainty, v. 5, n. 4, p. 297-323, 1992.

WU, G.; GONZALEZ, R. Curvature of the probability weighting function. Management Science, v. 42, p. 1676-1690, 1996.

\section{Apêndice A - Exemplo de questão}
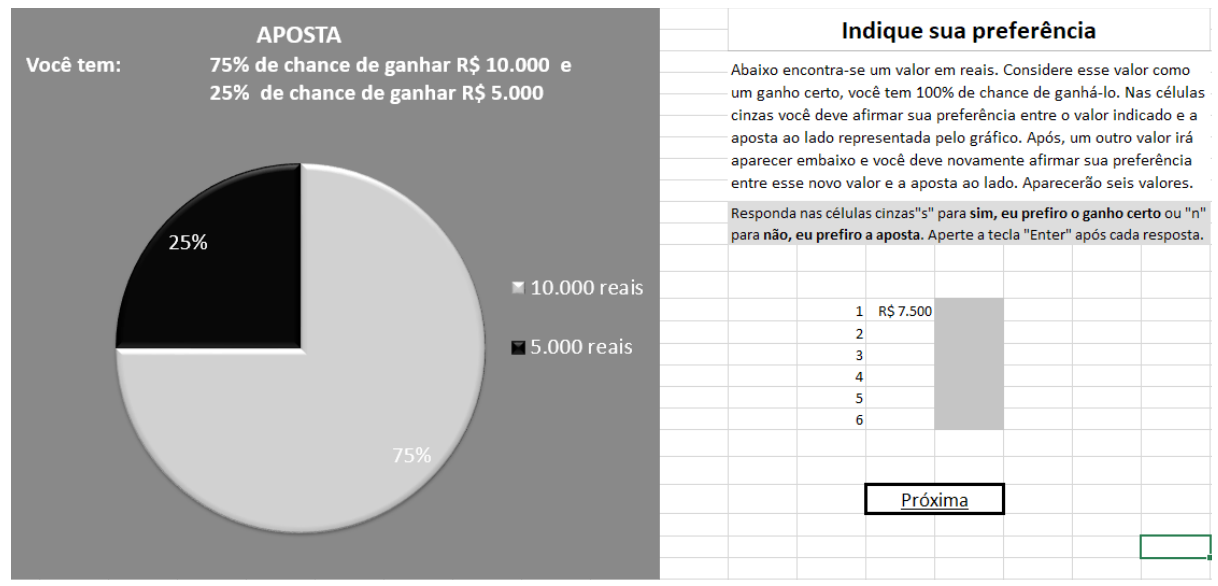

Fonte: Elaboração própria. 
Apêndice B

Tabela 6 - Resultado das estimações individuais

\begin{tabular}{|c|c|c|c|c|}
\hline Indivíduo & $\alpha$ & $\delta$ & $\gamma$ & $N^{o}$ de Obs. \\
\hline 1 & $0,49 * * *$ & $1,55 * *$ & $0,51 * * *$ & 36 \\
\hline 2 & $0,58 * * *$ & $1,07 * * *$ & $0,65 * * *$ & 42 \\
\hline 3 & $1,98^{*}$ & 0,28 & $0,46 * * *$ & 39 \\
\hline 4 & $0,71 * * *$ & $0,88 * * *$ & $0,47 * *$ & 38 \\
\hline 5 & $1,05 * *$ & $1,93 * * *$ & $0,70 * * *$ & 39 \\
\hline 6 & $1,14 * * *$ & $0,78 * *$ & $0,46 * * *$ & 42 \\
\hline 7 & $1,17 * * *$ & $0,41 * * *$ & $0,60 * * *$ & 38 \\
\hline 8 & $2,53^{*}$ & 0,20 & $0,42 * * *$ & 34 \\
\hline 9 & 8,54 & 0,00 & 3,43 & 28 \\
\hline 10 & $0,93 * * *$ & $1,02 * * *$ & $1,04 * * *$ & 42 \\
\hline 11 & $1,23 * * *$ & $1,40 * * *$ & $0,52 * * *$ & 41 \\
\hline 12 & $0,61 * * *$ & $1,27^{* * *}$ & $0,53 * * *$ & 31 \\
\hline 13 & $1,42 * * *$ & $0,58 * * *$ & $0,32 * * *$ & 41 \\
\hline 14 & $1,81 * * *$ & $0,39 * * *$ & $0,70 * * *$ & 41 \\
\hline 15 & $1,01 * *$ & $0,54 * * *$ & $0,31 * * *$ & 41 \\
\hline 16 & $1,60 * * *$ & $0,31 * *$ & $0,60 * * *$ & 41 \\
\hline 17 & $0,89 * * *$ & $2,40 * * *$ & $0,40 * * *$ & 40 \\
\hline 18 & $2,69 * *$ & $0,46^{*}$ & $0,25 * * *$ & 42 \\
\hline 19 & $0,45 * *$ & $0,19 * * *$ & $-0,03$ & 37 \\
\hline 20 & $1,35^{* *}$ & 0,24 & $0,46 * * *$ & 35 \\
\hline 21 & $2,46 * * *$ & $0,39^{*}$ & $0,40 * * *$ & 41 \\
\hline 22 & 4,58 & 0,00 & 2,81 & 36 \\
\hline 23 & $0,71 * * *$ & $1,21 * * *$ & $0,32 * * *$ & 42 \\
\hline 24 & Anulado & Anulado & Anulado & Anulado \\
\hline 25 & $2,95 * *$ & $0,04 * * *$ & 0,01 & 42 \\
\hline 26 & $0,62 * * *$ & $0,63 * *$ & $0,44 * * *$ & 40 \\
\hline 27 & $0,47^{* * *}$ & $2,26 * * *$ & 0,01 & 37 \\
\hline 28 & 67,97 & 0,00 & 0,11 & 42 \\
\hline 29 & 7,42 & 0,00 & 3,21 & 35 \\
\hline 30 & $0,81 * * *$ & $0,53 * * *$ & $0,76 * * *$ & 40 \\
\hline 31 & $0,48 * * *$ & $0,14^{*}$ & $1,15^{* * *}$ & 42 \\
\hline 32 & $0,82 * * *$ & $1,03 * * *$ & $0,82 * * *$ & 42 \\
\hline
\end{tabular}




\begin{tabular}{cllll}
\hline Indivíduo & $\boldsymbol{\alpha}$ & $\boldsymbol{\delta}$ & $\boldsymbol{\gamma}$ & $\mathbf{N}$ de Obs. \\
\hline 33 & 13,45 & 0,00 & 1,44 & 38 \\
34 & $1,17^{* * *}$ & $0,14^{* * *}$ & $0,07^{*}$ & 39 \\
35 & $2,03^{* * *}$ & 0,12 & $0,76^{* * *}$ & 37 \\
36 & $1,23^{* *}$ & 0,63 & $0,19^{* *}$ & 42 \\
37 & $1,02 * * *$ & $0,53^{* * *}$ & $0,44^{* * *}$ & 42 \\
38 & - & - & - & 41 \\
39 & 0,00 & $0,12^{* * *}$ & 0,00 & 42 \\
40 & $2,02^{* * *}$ & $0,28^{* *}$ & $0,63^{* * *}$ & 34 \\
41 & $1,14^{* * *}$ & $0,81^{* * *}$ & $0,51^{* * *}$ & 39 \\
42 & $0,89 * *$ & $1,16^{* * *}$ & $0,53^{* * *}$ & 42 \\
43 & $0,75^{* * *}$ & $0,25^{* * *}$ & 0,06 & 40 \\
44 & 0,41 & 1,04 & $-0,29$ & 31 \\
45 & 39,15 & 0,00 & 25,22 & 37 \\
46 & $1,32^{* * *}$ & $0,37^{* * *}$ & $0,85^{* * *}$ & 42 \\
47 & 33,09 & 0,00 & 2,53 & 29 \\
48 & 15,00 & 0,00 & 2,79 & 28 \\
49 & 0,14 & 0,05 & 0,86 & 41 \\
\hline
\end{tabular}

Fonte: Elaboração própria.

Nota: * = parâmetro significativo a 10\%; ** significativo a 5\%; ** * significativo a 1 \%.

\section{Apêndice C}

Tabela 7 - Testes-Z

\begin{tabular}{clcc}
\hline Parâmetro & \multicolumn{1}{c}{ Grupos comparados } & Valor do teste-Z & p-valor \\
\hline & Homens-mulheres & 1,58 & 0,11 \\
& Graduandos-mestrandos & $-0,33$ & 0,74 \\
& Graduandos-doutorandos & $-0,07$ & 0,94 \\
\cline { 2 - 3 }$\alpha$ & Graduandos-doutores & 1,88 & 0,06 \\
& Mestrandos-doutorandos & 0,14 & 0,88 \\
& Mestrandos-doutores & 1,55 & 0,12 \\
& Doutorandos-doutores & 0,95 & 0,34 \\
& Idade $\leq 25-25<$ Idade $<40$ & 0,82 & 0,41 \\
& Idade $\leq 25-$ Idade $\geq 40$ & $-0,65$ & 0,51 \\
& 25<Idade $<40-$ Idade $\geq 40$ & $-1,24$ & 0,21 \\
\hline
\end{tabular}




\begin{tabular}{clcc}
\hline Parâmetro & \multicolumn{1}{c}{ Grupos comparados } & Valor do teste-Z & p-valor \\
\hline & Homens-mulheres & 0,17 & 0,86 \\
& Graduandos-mestrandos & 2,16 & 0,03 \\
& Graduandos-doutorandos & $-0,46$ & 0,64 \\
Graduandos-doutores & $-0,59$ & 0,55 \\
& Mestrandos-doutorandos & $-1,53$ & 0,12 \\
& Mestrandos-doutores & $-2,46$ & 0,01 \\
Doutorandos-doutores & 0,14 & 0,88 \\
& Idade $\leq 25-25<$ Idade $<40$ & 1,71 & 0,08 \\
& Idade $\leq 25-$ Idade $\geq 40$ & $-0,11$ & 0,91 \\
25<Idade<40-Idade $\geq 40$ & $-1,49$ & 0,13 \\
\hline Homens-mulheres & 6,91 & 0,00 \\
Graduandos-mestrandos & 1,15 & 0,25 \\
Graduandos-doutorandos & 3,33 & 0,00 \\
Graduandos-doutores & $-5,63$ & 0,00 \\
& Mestrandos-doutorandos & 2,01 & 0,04 \\
Mestrandos-doutores & $-5,63$ & 0,00 \\
Doutorandos-doutores & $-6,97$ & 0,00 \\
Idade $\leq 25-25<$ Idade $<40$ & 2,09 & 0,03 \\
Idade $\leq 25-$ Idade $\geq 40$ & 0,43 & 0,66 \\
25<Idade<40-Idade $\geq 40$ & $-1,39$ & 0,16 \\
\hline
\end{tabular}

Fonte: Elaboração própria. 


\section{Apêndice D}

Tabela 8 - Mediana dos equivalentes de certeza para todos e por gênero

\begin{tabular}{|c|c|c|c|c|c|}
\hline Numeração & Aposta & Todos & Homens & Mulheres & $\begin{array}{c}\text { Valor } \\
\text { esperado }\end{array}$ \\
\hline 1 & $(200 ; 0,01: 0 ; 0,99)$ & 27 & 25 & 45 & (2) \\
\hline 2 & $(500 ; 0,01: 0 ; 0,99)$ & 43 & 35 & 59 & (5) \\
\hline 3 & $(1000 ; 0,01: 0 ; 0,99)$ & 102 & 102 & 78 & (10) \\
\hline 4 & $(3000 ; 0,01: 0 ; 0,99)$ & 164 & 141 & 398 & (30) \\
\hline 5 & $(500 ; 0,01: 250 ; 0,99)$ & 281 & 287 & 275 & $(252,5)$ \\
\hline 6 & $(3000 ; 0,01: 1000 ; 0,99)$ & 1250 & 1156 & 1406 & $(1020)$ \\
\hline 7 & $(200 ; 0,05: 0 ; 0,95)$ & 45 & 33 & 48 & (10) \\
\hline 8 & $(500 ; 0,05: 0 ; 0,95)$ & 78 & 82 & 59 & (25) \\
\hline 9 & $(1000 ; 0,05: 0 ; 0,95)$ & 117 & 117 & 180 & (50) \\
\hline 10 & $(3000 ; 0,05: 0 ; 0,95)$ & 258 & 211 & 305 & $(150)$ \\
\hline 11 & $(500 ; 0,05: 250 ; 0,95)$ & 293 & 299 & 258 & $(262,5)$ \\
\hline 12 & $(3000 ; 0,05: 1000 ; 0,95)$ & 1219 & 1281 & 1188 & (1100) \\
\hline 13 & $(200 ; 0,1: 0 ; 0,9)$ & 48 & 42 & 48 & (20) \\
\hline 14 & $(500 ; 0,1: 0 ; 0,9)$ & 98 & 105 & 98 & (50) \\
\hline 15 & $(1000 ; 0,1: 0 ; 0,9)$ & 211 & 203 & 242 & $(100)$ \\
\hline 16 & $(3000 ; 0,1: 0 ; 0,9)$ & 539 & 586 & 492 & (300) \\
\hline 17 & $(500 ; 0,1: 250 ; 0,9)$ & 293 & 299 & 287 & $(275)$ \\
\hline 18 & $(3000 ; 0,1: 1000 ; 0,9)$ & 1438 & 1406 & 1500 & $(1200)$ \\
\hline 19 & $(200 ; 0,25: 0 ; 0,75)$ & 70 & 70 & 48 & (50) \\
\hline 20 & $(500 ; 0,25: 0 ; 0,75)$ & 121 & 145 & 121 & (125) \\
\hline 21 & $(1000 ; 0,25: 0 ; 0,75)$ & 242 & 242 & 242 & $(250)$ \\
\hline 22 & $(3000 ; 0,25: 0 ; 0,75)$ & 727 & 727 & 375 & $(750)$ \\
\hline 23 & $(500 ; 0,25: 250 ; 0,75)$ & 299 & 311 & 275 & $(312,5)$ \\
\hline 24 & $(3000 ; 0,25: 1000 ; 0,75)$ & 1531 & 1500 & 1719 & $(1500)$ \\
\hline 25 & $(200 ; 0,5: 0 ; 0,5)$ & 95 & 95 & 89 & $(100)$ \\
\hline 26 & $(500 ; 0,5: 0 ; 0,5)$ & 191 & 199 & 105 & $(250)$ \\
\hline 27 & $(1000 ; 0,5: 0 ; 0,5)$ & 430 & 492 & 297 & $(500)$ \\
\hline 28 & $(3000 ; 0,5: 0 ; 0,5)$ & 1102 & 1383 & 961 & $(1500)$ \\
\hline 29 & $(500 ; 0,5: 250 ; 0,5)$ & 305 & 340 & 270 & (375) \\
\hline 30 & $(3000 ; 0,5: 1000 ; 0,5)$ & 1594 & 1594 & 1594 & $(2000)$ \\
\hline 31 & $(200 ; 0,75: 0 ; 0,25)$ & 139 & 139 & 111 & (150) \\
\hline
\end{tabular}


conclusão.

\begin{tabular}{clrrrr}
\hline Numeração & \multicolumn{1}{c}{ Aposta } & Todos & Homens & Mulheres & $\begin{array}{c}\text { Valor } \\
\text { esperado }\end{array}$ \\
\hline 32 & $(500 ; 0,75: 0 ; 0,25)$ & 297 & 301 & 254 & $(375)$ \\
33 & $(1000 ; 0,75: 0 ; 0,25)$ & 578 & 586 & 273 & $(750)$ \\
34 & $(3000 ; 0,75: 0 ; 0,25)$ & 1500 & 1523 & 1477 & $(2250)$ \\
35 & $(500 ; 0,75: 250 ; 0,25)$ & 357 & 369 & 340 & $(437,5)$ \\
36 & $(3000 ; 0,75: 1000 ; 0,25)$ & 2031 & 2031 & 1906 & $(2500)$ \\
37 & $(200 ; 0,99: 0 ; 0,01)$ & 180 & 184 & 170 & $(198)$ \\
38 & $(500 ; 0,99: 0 ; 0,01)$ & 473 & 477 & 410 & $(495)$ \\
39 & $(1000 ; 0,99: 0 ; 0,01)$ & 914 & 930 & 398 & $(990)$ \\
40 & $(3000 ; 0,99: 0 ; 0,01)$ & 2813 & 2836 & 2180 & $(2970)$ \\
41 & $(500 ; 0,99: 250 ; 0,01)$ & 463 & 469 & 451 & $(497,5)$ \\
42 & $(3000 ; 0,99: 1000 ; 0,01)$ & 2563 & 2781 & 2094 & $(2980)$ \\
\hline
\end{tabular}

Fonte: Elaboração própria.

Tabela 9 - Mediana dos equivalentes de certeza por escolaridade

\begin{tabular}{clrrrrr}
\hline $\begin{array}{c}\text { Nume- } \\
\text { ração }\end{array}$ & \multicolumn{1}{c}{ Aposta } & $\begin{array}{c}\text { Gra- } \\
\text { duandos }\end{array}$ & $\begin{array}{c}\text { Mes- } \\
\text { trandos }\end{array}$ & $\begin{array}{c}\text { Douto- } \\
\text { randos }\end{array}$ & $\begin{array}{c}\text { Dou- } \\
\text { tores }\end{array}$ & $\begin{array}{c}\text { Valor } \\
\text { esperado }\end{array}$ \\
\hline 1 & $(200 ; 0,01: 0 ; 0,99)$ & 33 & 30 & 19 & 11 & $(2)$ \\
2 & $(500 ; 0,01: 0 ; 0,99)$ & 66 & 27 & 70 & 51 & $(5)$ \\
3 & $(1000 ; 0,01: 0 ; 0,99)$ & 109 & 55 & 94 & 55 & $(10)$ \\
4 & $(3000 ; 0,01: 0 ; 0,99)$ & 211 & 117 & 211 & 23 & $(30)$ \\
5 & $(500 ; 0,01: 250 ; 0,99)$ & 275 & 275 & 316 & 287 & $(252,5)$ \\
6 & $(3000 ; 0,01: 1000 ; 0,99)$ & 1281 & 1094 & 1531 & 1156 & $(1020)$ \\
7 & $(200 ; 0,05: 0 ; 0,95)$ & 45 & 23 & 45 & 23 & $(10)$ \\
8 & $(500 ; 0,05: 0 ; 0,95)$ & 82 & 82 & 66 & 59 & $(25)$ \\
9 & $(1000 ; 0,05: 0 ; 0,95)$ & 117 & 117 & 133 & 117 & $(50)$ \\
10 & $(3000 ; 0,05: 0 ; 0,95)$ & 305 & 211 & 492 & 164 & $(150)$ \\
11 & $(500 ; 0,05: 250 ; 0,95)$ & 299 & 299 & 287 & 270 & $(262,5)$ \\
12 & $(3000 ; 0,05: 1000 ; 0,95)$ & 1219 & 1344 & 1313 & 1094 & $(1100)$ \\
13 & $(200 ; 0,1: 0 ; 0,9)$ & 50 & 48 & 36 & 23 & $(20)$ \\
14 & $(500 ; 0,1: 0 ; 0,9)$ & 109 & 59 & 129 & 59 & $(50)$ \\
15 & $(1000 ; 0,1: 0 ; 0,9)$ & 242 & 211 & 195 & 180 & $(100)$ \\
16 & $(3000 ; 0,1: 0 ; 0,9)$ & 586 & 492 & 820 & 352 & $(300)$ \\
17 & $(500 ; 0,1: 250 ; 0,9)$ & 293 & 322 & 311 & 287 & $(275)$ \\
\hline & & & & & & continua...
\end{tabular}




\begin{tabular}{|c|c|c|c|c|c|c|}
\hline $\begin{array}{l}\text { Nume- } \\
\text { ração }\end{array}$ & Aposta & $\begin{array}{c}\text { Gra- } \\
\text { duandos }\end{array}$ & $\begin{array}{c}\text { Mes- } \\
\text { trandos }\end{array}$ & $\begin{array}{l}\text { Douto- } \\
\text { randos }\end{array}$ & $\begin{array}{l}\text { Dou- } \\
\text { tores }\end{array}$ & $\begin{array}{c}\text { Valor } \\
\text { esperado }\end{array}$ \\
\hline 18 & $(3000 ; 0,1: 1000 ; 0,9)$ & 1469 & 1406 & 1281 & 1344 & (1200) \\
\hline 19 & $(200 ; 0,25: 0 ; 0,75)$ & 70 & 48 & 95 & 48 & $(50)$ \\
\hline 20 & $(500 ; 0,25: 0 ; 0,75)$ & 168 & 113 & 145 & 113 & $(125)$ \\
\hline 21 & $(1000 ; 0,25: 0 ; 0,75)$ & 297 & 117 & 289 & 227 & $(250)$ \\
\hline 22 & $(3000 ; 0,25: 0 ; 0,75)$ & 891 & 352 & 984 & 680 & $(750)$ \\
\hline 23 & $(500 ; 0,25: 250 ; 0,75)$ & 316 & 275 & 287 & 275 & $(312,5)$ \\
\hline 24 & $(3000 ; 0,25: 1000 ; 0,75)$ & 1719 & 1563 & 1406 & 1406 & $(1500)$ \\
\hline 25 & $(200 ; 0,5: 0 ; 0,5)$ & 98 & 70 & 95 & 95 & (100) \\
\hline 26 & $(500 ; 0,5: 0 ; 0,5)$ & 246 & 121 & 137 & 121 & $(250)$ \\
\hline 27 & $(1000 ; 0,5: 0 ; 0,5)$ & 492 & 242 & 266 & 227 & $(500)$ \\
\hline 28 & $(3000 ; 0,5: 0 ; 0,5)$ & 1383 & 727 & 1172 & 1148 & $(1500)$ \\
\hline 29 & $(500 ; 0,5: 250 ; 0,5)$ & 334 & 287 & 299 & 299 & (375) \\
\hline 30 & $(3000 ; 0,5: 1000 ; 0,5)$ & 1625 & 1344 & 1469 & 1906 & $(2000)$ \\
\hline 31 & $(200 ; 0,75: 0 ; 0,25)$ & 148 & 102 & 145 & 120 & (150) \\
\hline 32 & $(500 ; 0,75: 0 ; 0,25)$ & 363 & 293 & 168 & 340 & (375) \\
\hline 33 & $(1000 ; 0,75: 0 ; 0,25)$ & 602 & 492 & 328 & 758 & $(750)$ \\
\hline 34 & $(3000 ; 0,75: 0 ; 0,25)$ & 1711 & 727 & 1758 & 1336 & $(2250)$ \\
\hline 35 & $(500 ; 0,75: 250 ; 0,25)$ & 369 & 328 & 357 & 334 & $(437,5)$ \\
\hline 36 & $(3000 ; 0,75: 1000 ; 0,25)$ & 2031 & 1750 & 1906 & 2031 & $(2500)$ \\
\hline 37 & $(200 ; 0,99: 0 ; 0,01)$ & 180 & 170 & 192 & 192 & (198) \\
\hline 38 & $(500 ; 0,99: 0 ; 0,01)$ & 484 & 441 & 441 & 441 & $(495)$ \\
\hline 39 & $(1000 ; 0,99: 0 ; 0,01)$ & 898 & 898 & 945 & 914 & (990) \\
\hline 40 & $(3000 ; 0,99: 0 ; 0,01)$ & 2836 & 2789 & 2836 & 2367 & (2970) \\
\hline 41 & $(500 ; 0,99: 250 ; 0,01)$ & 480 & 463 & 404 & 416 & $(497,5)$ \\
\hline 42 & $(3000 ; 0,99: 1000 ; 0,01)$ & 2094 & 2719 & 2906 & 2906 & $(2980)$ \\
\hline
\end{tabular}

Fonte: Elaboração própria. 
Tabela 10 - Mediana dos equivalentes de certeza por idade

\begin{tabular}{|c|c|c|c|c|c|}
\hline Numeração & Aposta & $\begin{array}{r}\text { Idade } \\
25\end{array}$ & $\begin{array}{r}25< \\
\text { Idade }< \\
40\end{array}$ & $\begin{array}{r}\text { Idade } \\
\geq 40\end{array}$ & $\begin{array}{c}\text { Valor } \\
\text { esperado }\end{array}$ \\
\hline 1 & $(200 ; 0,01: 0 ; 0,99)$ & 30 & 17 & 39 & (2) \\
\hline 2 & $(500 ; 0,01: 0 ; 0,99)$ & 59 & 20 & 82 & (5) \\
\hline 3 & $(1000 ; 0,01: 0 ; 0,99)$ & 55 & 39 & 164 & (10) \\
\hline 4 & $(3000 ; 0,01: 0 ; 0,99)$ & 117 & 70 & 398 & (30) \\
\hline 5 & $(500 ; 0,01: 250 ; 0,99)$ & 275 & 287 & 322 & $(252,5)$ \\
\hline 6 & $(3000 ; 0,01: 1000 ; 0,99)$ & 1281 & 1094 & 1406 & $(1020)$ \\
\hline 7 & $(200 ; 0,05: 0 ; 0,95)$ & 23 & 20 & 47 & (10) \\
\hline 8 & $(500 ; 0,05: 0 ; 0,95)$ & 59 & 51 & 98 & (25) \\
\hline 9 & $(1000 ; 0,05: 0 ; 0,95)$ & 148 & 63 & 219 & (50) \\
\hline 10 & $(3000 ; 0,05: 0 ; 0,95)$ & 305 & 164 & 609 & (150) \\
\hline 11 & $(500 ; 0,05: 250 ; 0,95)$ & 299 & 293 & 275 & $(262,5)$ \\
\hline 12 & $(3000 ; 0,05: 1000 ; 0,95)$ & 1219 & 1281 & 1250 & (1100) \\
\hline 13 & $(200 ; 0,1: 0 ; 0,9)$ & 48 & 39 & 41 & (20) \\
\hline 14 & $(500 ; 0,1: 0 ; 0,9)$ & 98 & 51 & 125 & (50) \\
\hline 15 & $(1000 ; 0,1: 0 ; 0,9)$ & 242 & 94 & 227 & $(100)$ \\
\hline 16 & $(3000 ; 0,1: 0 ; 0,9)$ & 727 & 305 & 492 & (300) \\
\hline 17 & $(500 ; 0,1: 250 ; 0,9)$ & 287 & 293 & 311 & (275) \\
\hline 18 & $(3000 ; 0,1: 1000 ; 0,9)$ & 1531 & 1281 & 1375 & (1200) \\
\hline 19 & $(200 ; 0,25: 0 ; 0,75)$ & 70 & 48 & 88 & (50) \\
\hline 20 & $(500 ; 0,25: 0 ; 0,75)$ & 137 & 105 & 133 & (125) \\
\hline 21 & $(1000 ; 0,25: 0 ; 0,75)$ & 242 & 172 & 266 & (250) \\
\hline 22 & $(3000 ; 0,25: 0 ; 0,75)$ & 750 & 305 & 727 & (750) \\
\hline 23 & $(500 ; 0,25: 250 ; 0,75)$ & 299 & 287 & 287 & $(312,5)$ \\
\hline 24 & $(3000 ; 0,25: 1000 ; 0,75)$ & 1719 & 1500 & 1406 & $(1500)$ \\
\hline 25 & $(200 ; 0,5: 0 ; 0,5)$ & 98 & 47 & 95 & (100) \\
\hline 26 & $(500 ; 0,5: 0 ; 0,5)$ & 219 & 121 & 141 & (250) \\
\hline 27 & $(1000 ; 0,5: 0 ; 0,5)$ & 492 & 117 & 242 & $(500)$ \\
\hline 28 & $(3000 ; 0,5: 0 ; 0,5)$ & 1383 & 820 & 1336 & $(1500)$ \\
\hline 29 & $(500 ; 0,5: 250 ; 0,5)$ & 311 & 299 & 299 & (375) \\
\hline 30 & $(3000 ; 0,5: 1000 ; 0,5)$ & 1656 & 1219 & 1688 & (2000) \\
\hline 31 & $(200 ; 0,75: 0 ; 0,25)$ & 144 & 108 & 133 & (150) \\
\hline 32 & $(500 ; 0,75: 0 ; 0,25)$ & 363 & 219 & 203 & (375) \\
\hline
\end{tabular}




\begin{tabular}{clrrrr} 
conclusão. & Aposta & $\begin{array}{r}\text { Idade } \\
\mathbf{2 5}\end{array}$ & $\begin{array}{r}\mathbf{2 5}< \\
\text { Idade }< \\
\mathbf{4 0}\end{array}$ & $\begin{array}{r}\text { Idade } \\
\mathbf{2} \mathbf{4 0}\end{array}$ & $\begin{array}{c}\text { Valor } \\
\text { esperado }\end{array}$ \\
\hline 33 & $(1000 ; 0,75: 0 ; 0,25)$ & 602 & 445 & 492 & $(750)$ \\
34 & $(3000 ; 0,75: 0 ; 0,25)$ & 1945 & 703 & 1547 & $(2250)$ \\
35 & $(500 ; 0,75: 250 ; 0,25)$ & 375 & 334 & 346 & $(437,5)$ \\
36 & $(3000 ; 0,75: 1000 ; 0,25)$ & 2031 & 1594 & 1906 & $(2500)$ \\
37 & $(200 ; 0,99: 0 ; 0,01)$ & 180 & 127 & 189 & $(198)$ \\
38 & $(500 ; 0,99: 0 ; 0,01)$ & 484 & 441 & 434 & $(495)$ \\
39 & $(1000 ; 0,99: 0 ; 0,01)$ & 898 & 703 & 914 & $(990)$ \\
40 & $(3000 ; 0,99: 0 ; 0,01)$ & 2836 & 2086 & 2742 & $(2970)$ \\
41 & $(500 ; 0,99: 250 ; 0,01)$ & 469 & 398 & 410 & $(497,5)$ \\
42 & $(3000 ; 0,99: 1000 ; 0,01)$ & 2281 & 1781 & 2906 & $(2980)$ \\
\hline
\end{tabular}

Fonte: Elaboração própria.

Recebido em: 19/01/2017. Aceito em: 30/10/2017. 